\title{
The heat shock response in neurons and astroglia and its role in neurodegenerative diseases
}

\author{
Rebecca San Gil, Lezanne Ooi, Justin J. Yerbury and Heath Ecroyd
}

\begin{abstract}
Protein inclusions are a predominant molecular pathology found in numerous neurodegenerative diseases, including amyotrophic lateral sclerosis and Huntington's disease. Protein inclusions form in discrete areas of the brain characteristic to the type of neurodegenerative disease, and coincide with the death of neurons in that region (e.g. spinal cord motor neurons in amyotrophic lateral sclerosis). This suggests that the process of protein misfolding leading to inclusion formation is neurotoxic, and that cell-autonomous and non-cell autonomous mechanisms that maintain protein homeostasis (proteostasis) can, at times, be insufficient to prevent protein inclusion formation in the central nervous system. The heat shock response is a pro-survival pathway induced under conditions of cellular stress that acts to maintain proteostasis through the up-regulation of heat shock proteins, a superfamily of molecular chaperones, other co-chaperones and mitotic regulators. The kinetics and magnitude of the heat shock response varies in a stress- and cell-type dependent manner. It remains to be determined if and/or how the heat shock response is activated in the different cell-types that comprise the central nervous system (e.g. neurons and astroglia) in response to protein misfolding events that precede cellular dysfunctions in neurodegenerative diseases. This is particularly relevant considering emerging evidence demonstrating the non-cell autonomous nature of amyotrophic lateral sclerosis and Huntington's disease (and other neurodegenerative diseases) and the destructive role of astroglia in disease progression. This review highlights the complexity of heat shock response activation and addresses whether neurons and glia sense and respond to protein misfolding and aggregation associated with neurodegenerative diseases, in particular Huntington's disease and amyotrophic lateral sclerosis, by inducing a pro-survival heat shock response.
\end{abstract}

Keywords: Neurodegeneration, Amyotrophic lateral sclerosis, Huntington's disease, Proteostasis, Heat shock response, Heat shock factor 1, Motor neurons, Striatal neurons, Astroglia

\section{Background}

Neurodegenerative diseases (NDs), such as amyotrophic lateral sclerosis (ALS) and Huntington's disease (HD), are thought to manifest through either a loss of function of the wild-type (WT) protein or toxic gain-of-function as a result of its oligomerization and aggregation [1]. The neuronspecific degeneration observed in discrete regions of the brain in NDs suggests that specific neuronal sub-types are particularly vulnerable to protein misfolding and aggregation. This may be the result of: (i) a post-mitotic inability to

\footnotetext{
* Correspondence: heathe@uow.edu.au

Illawarra Health and Medical Research Institute and School of Biological Sciences, University of Wollongong, Northfields Ave, Wollongong 2522, Australia
}

dilute toxic protein species through cell-division; (ii) an age-related decline in the systems that maintain protein homeostasis (proteostasis); (iii) a failure of the proteostasis network to detect pathogenic protein aggregates; or (iv) a combination of these factors [2-4].

Molecular chaperones are a central component of the proteostasis network as they act to facilitate the correct folding of nascent polypeptides, maintain partially-folded protein intermediates in folding-competent states and re-fold damaged proteins [5-8]. A recent comprehensive analysis of the human "chaperome" identified 332 chaperone genes, 142 of which correspond to the heat shock protein subfamilies (Hsp90, Hsp70, Hsp60, Hsp40 and sHsps) [4]. The Hsps are a family of evolutionarily 
conserved chaperones with diverse functions in proteostasis. In addition to their well characterized molecular chaperone functions, Hsps also stabilize the cytoskeleton, regulate stress responses, mitigate apoptotic signalling and shuttle damaged proteins for degradation by the ubiquitin proteasome system or by autophagy $[9,10]$.

There is a dramatic up-regulation of Hsp expression in cells upon induction of the heat shock response (HSR). The activation of this pathway is a primary defense mechanism that protects cells from stress conditions that promote protein misfolding, aggregation and cell death. It has previously been shown that components of the HSR may be neuroprotective due to their ability to interact with the earliest misfolded proteins that trigger pathogenic aggregation. Indeed, numerous studies have shown that Hsps can prevent the aggregation of various disease-associated proteins in vitro, for example, mutant superoxide dismutase 1 (SOD1) in ALS [11-15]. Heat shock proteins can also interact with pathogenic proteins in vivo and have been found co-localized with plaques and inclusions in transgenic mouse models of NDs and patient post-mortem tissues [16-19]. For example, Hsc70 was co-localized with inclusion bodies in spinal cord sections of SOD1 $1^{\mathrm{G} 93 \mathrm{~A}}, \mathrm{SOD} 1^{\mathrm{G} 85 \mathrm{R}}$, and SOD1 $1^{\mathrm{G} 37 \mathrm{R}}$ transgenic mice, and human sporadic ALS cases [17]. The co-localization of Hsps with inclusions suggests that Hsps are diverted into inclusions and therefore unavailable to perform normal "housekeeping" functions.

Little is known about how and/or if the HSR is induced in neuronal and glial cells by pathogenic protein aggregation. Elucidating whether the HSR is triggered by protein aggregation and, if so, the mechanism(s) by which this occurs, is important for future work aimed at developing proteostasis-modulating therapeutics to ameliorate ND pathologies. The objectives of this review are to summarize what is currently known about the activation of the HSR in different tissues and cell-types during cellular stress, and explore evidence regarding the involvement of the HSR in rescuing neurons and astroglia from pathological stress associated with NDs. Due to the diversity in how different NDs manifest in the CNS (i.e. dysfunction of different neuronal and non-neuronal cell types across different brain regions), this review seeks to provide a comprehensive summary of the literature surrounding the HSR in cells associated with HD and ALS. We conclude by drawing correlations between our core findings in the HD and ALS literature with NDs in general. In doing so, progress in this field of research is evaluated, gaps in our knowledge are highlighted and possible solutions are discussed.

\section{The HSR}

Proteotoxic cellular insults have a common effect of damaging proteins and inducing the accumulation of partially-folded protein intermediates. This in turn can activate transcription factors and induce the HSR. The human genome encodes four heat shock transcription factors (HSF), HSF1 - HSF4, which have unique and overlapping functions [20]. Heat shock transcription factor 1 is the prime integrator of transcriptional responses during stress and is responsible for the induction of the HSR. The role of HSF1 in the activation and attenuation of the HSR in cells under conditions of cellular stress is discussed briefly below.

\section{Heat shock transcription factor 1}

Heat shock transcription factor 1 is constitutively expressed in most tissues and cell types and, apart from its role in the HSR, is involved in a wide range of processes including organismal development, insulin signaling and cancer metastasis (for recent comprehensive reviews see [21, 22]). Posttranslational modifications are critical in modulating the activity of HSF1 [23]: it can be acetylated [24, 25], SUMOylated [26] and extensively phosphorylated [27] (Fig. 1). The type and site of each post-translational modification have been predominantly identified by proteomic mass spectrometry and site-directed mutagenesis experiments [22, $23,28]$. Whilst the activation of HSF1 is complex and only partially understood, previous studies highlight the importance post-translational modifications play in stabilising, activating and inhibiting the transcriptional activity of HSF1 [28]. For example, conversion of HSF1 into a transcriptionally active trimer occurs concurrently with extensive posttranslational modifications including stress-inducible hyperphosphorylation of S230, S326 and T142 [29-31], such that hyperphosphorylated HSF1 is used as a marker of HSF1 activation [32-35]. Aside from (extensive) phosphorylation, acetylation and SUMOylation of HSF1 also play important roles in regulating the strength and duration of the HSR (for comprehensive reviews see [21, 36]).

\section{HSR activation and attenuation}

Under conditions of cellular stress, HSF1 monomers form activated homo-trimers and translocate into the nucleus. Trimerization is mediated through the formation of leucine zippers on adjacent HSF1 oligomerization domains (Fig. 2) [37, 38]. Activated HSF1 trimers bind to cis-regulatory elements on DNA composed of nGAAn pentamers (where $\mathrm{n}$ is any base), collectively called heat shock elements [39-42]. The extent and duration of HSF1-mediated transcription is influenced by the number of heat shock elements, the exact sequence of nGAAn pentamers in the promoter regions of HSF1 target genes, and post-translational modifications on HSF1 itself [21]. In addition to the rapid up-regulation of Hsp expression in response to cellular stress, HSF1 also coordinates the expression of many transcriptional and translational regulators, co-chaperones, ubiquitin, signaling molecules and mitotic regulators [21, 43, 44]. 


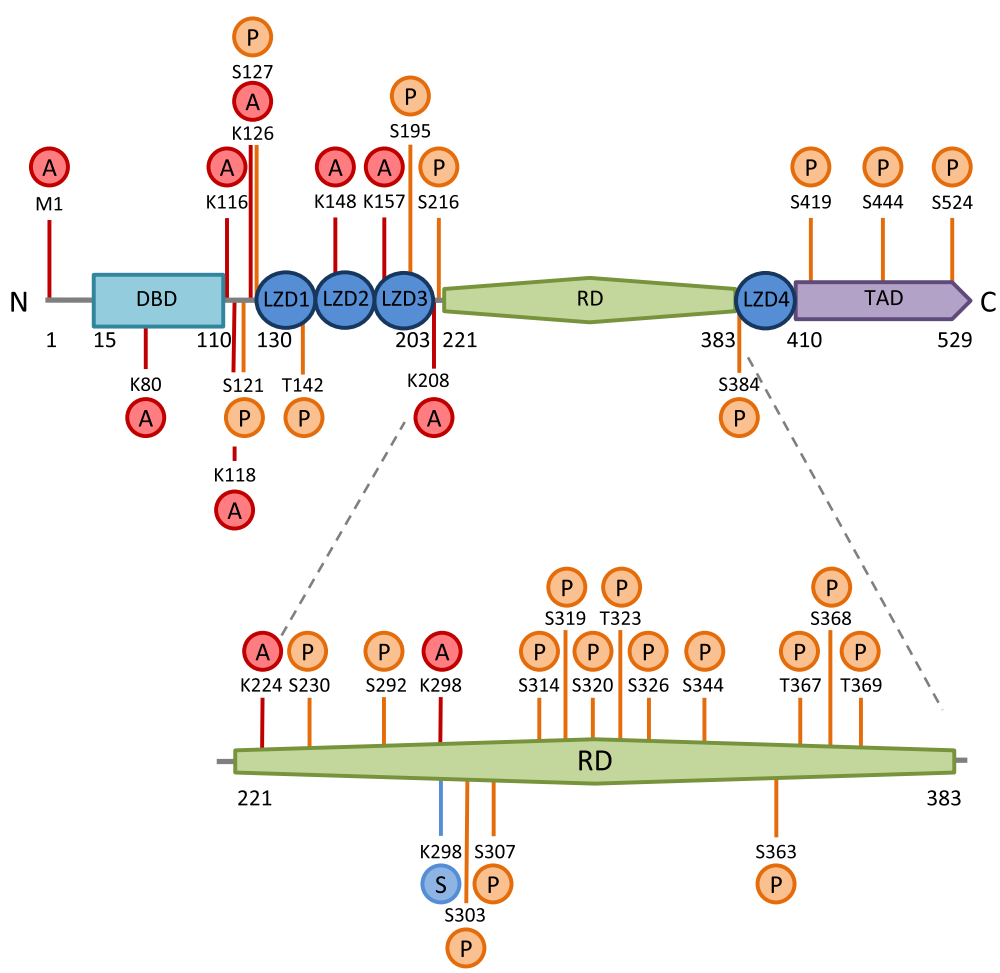

Fig. 1 Post-translational modifications of HSF1 in relation to the functional domains in the protein. The HSF1 protein consists of a DNA-binding domain (DBD), four leucine zipper domains (LZD), a regulatory domain (RD) and a transactivating domain (TAD). The proposed sites of serine/ threonine phosphorylation (P), lysine acetylation (A) and phosphorylation-dependent lysine SUMOylation (S) are marked on the HSF1 amino acid chain. These post-translational modifications are mediated by numerous kinases, acetylases and SUMOylases and act to modulate the stabilization and activity of HSF1 and thus the strength and duration of the HSR

Heat shock factor 1-mediated transcription is attenuated by an auto-regulatory mechanism, whereby HSF1-induced Hsps competitively inhibit HSF1 trimer activity [22, 28]. This negative feedback loop provides an important mechanism by which cells can regulate the activation and attenuation of an HSR via the presence and concentration of Hsps in the cell. The trimerisation of HSF1 is suppressed by interaction of the monomer with a multichaperone complex composed of Hsp90, co-chaperone p23 and immunophilin FK506-binding protein 5 [45, 46]. In addition, the chaperonin $\mathrm{TRiC} / \mathrm{CCT}$ can also interact with HSF1 to inhibit its activation [47]. Active HSF1 trimers in the nucleus can be inhibited by the binding of Hsp70 and its co-chaperone Hsp40, possibly through recruitment of the Hsp70-interacting transcriptional corepressor, CoREST [48, 49]. Further characterization of the mechanisms that modulate HSF1 activity (and therefore, the HSR) may help elucidate additional targets for therapies that could be used to boost the HSR in the context of disease such as NDs.

\section{The HSR in the mammalian CNS}

In mammals, the HSR varies both in terms of kinetics (i.e. how fast stress-induced transcripts are generated) and magnitude (i.e. the fold increase in Hsp levels) between tissues and even between cells in the same tissue [50-52]. Analysis of the human "chaperome" shows that the constitutive expression of housekeeping chaperones and co-chaperones varies between tissues [52]. For example, sHsps are overrepresented in skeletal and cardiac muscle compared to the brain [52]. With regard to inducing the HSR, whole organism hyperthermia results in an HSR that varies substantially across tissues types [50]. For example, in heat-stressed rats, the kinetics of the response and magnitude of induction where found to vary between the brain, liver and skin when assessed over time by northern blot of Hsp70 and Hsp27 stressinduced mRNA [50]. Moreover, cells in the same tissue can display different capacities to induce the HSR. For example, cultured astrocytes elicit faster and higher levels of $\mathrm{Hsp} 70$ expression after heat shock $\left(45{ }^{\circ} \mathrm{C}\right.$ for $30 \mathrm{~min})$ compared to cultured cortical neurons [51]. These studies strongly suggest that the capacity of a cell to sense stress and elicit an HSR differs in a cell-type dependent manner.

An attenuated HSR may be an intrinsic characteristic of neurons [35, 53-55]. Indeed, this hypothesis is supported by several animal studies that have challenged 


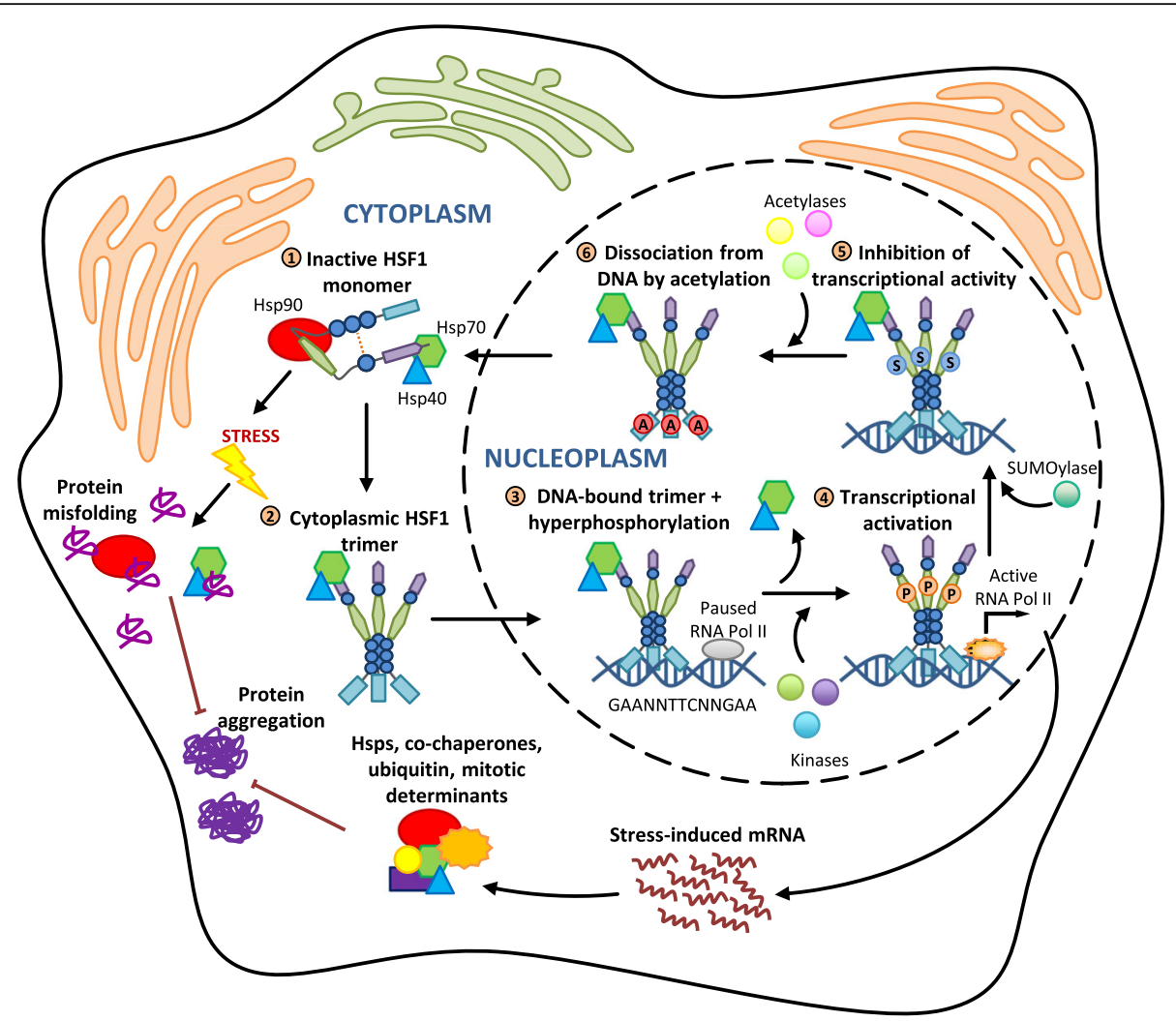

Fig. 2 The activation of HSF1 and its binding to DNA is regulated by a multi-step pathway that involves nuclear accumulation, intramolecular and intermolecular protein interactions, and post-translational modifications. (1) In the absence of stress, HSF1 is maintained in a monomeric state through the regulatory actions of several post-translational modifications, intramolecular contacts, and interactions with Hsps in inhibitory complexes. Cellular stress results in the accumulation of misfolded and damaged proteins, which compete with HSF1 for binding to Hsps. (2) HSF1 monomers are released and undergo a conformational change conducive to trimerization. (3) Concurrent nuclear accumulation, HSE-binding and hyperphosphorylation of trimeric HSF1 occur. (4) This process releases RNA Polll from a paused to an active state to initiate the transcription of stress-induced genes. (5) SUMOylation at K298 and binding of Hsp40/Hsp70 represses the transcriptional activity of HSF1 trimers. (6) Acetylation at K80 disrupts HSF1 binding to DNA and HSF1 trimers dissociate and re-join the monomeric pool in the cytosol. Stress-inducible Hsps participate in a negative-feedback loop to inhibit further HSF1 activation

rodents with hyperthermia or ischemic injury and shown that neurons do not induce Hsp70 expression after exposure to these stressors, whereas surrounding astroglial cells do $[35,51,54-59]$. These seminal studies show that under conditions of acute cellular stress, neurons are inherently poor activators of the HSR, whereas astroglia readily activate the HSR. This prompts the question of whether neuronal and astroglial cells respond to chronic ND-relevant stressors (such as protein aggregation) and, if so, whether there is a difference in the response of neuronal and astroglial cells to this stress. In an attempt to address these questions, the remainder of this review deals with what is known about HSR activation in the context of two NDs, HD and ALS.

\section{Huntington's Disease}

Huntington's disease is characterized by the formation of intracellular inclusions composed primarily of the ubiquitous protein huntingtin $(\mathrm{Htt})$ and by the subsequent death of striatal medium spiny neurons and cortical pyramidal neurons $[60,61]$. The genetic basis for the pathogenesis of $\mathrm{HD}$ is a CAG codon repeat expansion in the Huntingtin (HTT) gene, which leads to a mutant protein that contains an expanded poly-glutamine (polyQ) sequence [62]. Expansions of the polyQ tract beyond 36 glutamines result in an aggregation-prone Htt protein; the length of the polyQ-expansion correlates with the age of disease onset and severity (i.e. the longer the polyQ tract, the earlier the onset of disease and the more rapid the disease progression) [63]. Well-characterized cell and transgenic mouse models of HD have been used in investigations into the impact of the HSR on the pathogenicity of polyQexpansions.

PolyQ-expanded Htt may interact differently with the proteostasis network compared to other diseaseassociated proteins. Evidence for this comes from studies that have shown that polyQ-expanded $\mathrm{Htt}^{103 \mathrm{Q}}$ (i.e. Htt with a polyQ stretch of 103 glutamines) partitions 
exclusively into perivacuolar inclusion bodies (IPODs: Insoluble PrOtein Deposits) that store terminally aggregated proteins [64]. Fluorescence recovery after photobleaching experiments showed that $\mathrm{Htt}^{103 \mathrm{Q}}$ proteins sequestered into IPODs are immobile [65] indicating that sequestration into IPODs prevents possible interactions of the aggregated protein with components of the proteostasis network, exacerbating the formation of inclusions in cells $[64,66]$. Recent evidence also suggests that $\mathrm{Htt}$ inclusion body formation deactivates apoptosis and results in slow necrotic cell death [67]. This contrasts with quality control partitioning of other aggregation-prone disease-associated proteins, such as SOD1, which accumulate in juxtanuclear compartments (JUNQ: JUxtaNuclear Quality control) for presentation to molecular chaperones for re-folding and/or the ubiquitin proteasome system for degradation $[64,66,68,69]$. Therefore, findings pertaining to the HSR in the context of HD may uniquely apply to this ND due to the propensity of polyQ-expanded $\mathrm{Htt}$ to misfold directly into terminal aggregates and become stored in IPODs (as opposed to the JUNQ).

\section{The HSR in striatal neurons}

The expression and cellular accumulation of pathogenic polyQ-expanded $\mathrm{Htt}$ is not sufficient to induce an HSR in cell and animal models of HD. The expression of $\mathrm{Htt}^{91 \mathrm{Q}}$ does not induce an HSR (as assessed by an Hsp70 promoter driven EGFP expression construct) [70]. Notably, the expression of $\mathrm{Htt}^{111 \mathrm{Q}}$ in striatal cells was not sufficient to up-regulate Hsp expression nor activate HSF1 [32]. Likewise, primary cultures of rat cortical and striatal neurons expressing $\mathrm{Htt}^{111 \mathrm{Q}}$ showed low levels of Hsp70 mRNA transcripts and protein compared to cerebellar granule cells, which have high levels of Hsp70 and are resistant to degeneration [71]. Studies using transgenic mouse models of HD have demonstrated that there is a reduction in Hsp70 (and other molecular chaperones) in the brain as the disease progresses (Table 1) [72]. Taken together, these results show that cells expressing polyQ-expanded $\mathrm{Htt}$ do not sense or respond to this aggregation-prone protein by inducing an HSR.

The expression of polyQ-expanded $\mathrm{Htt}$ sensitizes neurons to heat stress $[32,73]$. Heat shock $\left(42{ }^{\circ} \mathrm{C}\right.$ for $6 \mathrm{~h})$ of primary murine striatal neurons expressing pathogenic $\mathrm{Htt}^{111 \mathrm{Q}}$ resulted in a 6 -fold increase in caspase activity compared to heat shocked cells expressing non-pathogenic $\mathrm{Htt}^{7 \mathrm{Q}}$ [32]. Furthermore, cells expressing $\mathrm{Htt}^{111 \mathrm{Q}}$ had a reduced capacity to express Hsp70, Hsp25 (the mouse orthologue of Hsp27) and Hsp90 after heat shock compared to those expressing $\mathrm{Htt}^{7 \mathrm{Q}}$ [32]. These findings suggest that expression of polyQexpanded $\mathrm{Htt}$ attenuates the capacity of striatal neurons to up-regulate the expression of Hsps after heat shock, which is normally a very strong activator of the HSR.

Based on these findings, it is pertinent to question whether the observed inability of striatal neurons to induce an HSR in the context of HD is the result of insufficient levels of HSF1, a failure to activate HSF1, a lack of HSF1 binding to DNA, or a combination of these deficiencies (Fig. 3). Quantification of total HSF1 protein by immunoblot demonstrated that primary striatal neurons expressing $\mathrm{Htt}^{111 \mathrm{Q}}$, and the striata and cerebella of HD mouse models, have lower total HSF1 levels compared to controls [32]. New evidence implicates CK $2 \alpha$ '

Table 1 List of Hsps and whether their expression is up-regulated $(\uparrow)$, down-regulated $(\downarrow)$, or not changed (No $\Delta$ ) across rodent models of HD compared to transgenic WT or non-transgenic mouse controls

\begin{tabular}{|c|c|c|c|}
\hline Hsps & Transgenic disease models & Tissue or cell type & Reference \\
\hline HSF1 & STHdh(Q111) knock-in mice & IB: $80 \% \downarrow$ striatal and cerebellar tissue homogenates & {$[32,74]$} \\
\hline \multirow[t]{2}{*}{ aB-c (HSPB5) } & $\mathrm{R} 6 / 2$ & IB: No $\Delta$ whole brain homogenates & [72] \\
\hline & Htt-N171-82Q & IB: No $\Delta$ spinal cord homogenates & [79] \\
\hline \multirow[t]{2}{*}{ Hsp25 (HSPB1) } & $\mathrm{R} 6 / 2$ & IB: No $\Delta$ whole brain homogenates & [72] \\
\hline & Htt-N171-82Q & IB: No $\Delta$ spinal cord homogenates & [79] \\
\hline Hsp40 & $\mathrm{R} 6 / 2$ & $\begin{array}{l}\text { IB: } 60 \% \downarrow \text { Hdj1 whole brain homogenates } \\
\text { IB: } 25 \% \downarrow H d j 2 \text { whole brain homogenates }\end{array}$ & [72] \\
\hline Hsp60 & $\mathrm{R} 6 / 2$ & $\begin{array}{l}\text { LC-MS: } 4 \text {-fold } \downarrow \text { in protein abundance in the cortex } \\
\text { LC-MS: } 4 \text {-fold } \uparrow \text { in protein abundance in the striatum }\end{array}$ & [80] \\
\hline \multirow[t]{2}{*}{ Hsp70 } & STHdh(Q111) knock-in mice & IB: $80 \% \downarrow$ striatal and cerebellar tissue homogenates & [32] \\
\hline & $\mathrm{R} 6 / 2$ & $\begin{array}{l}\text { IB: } \downarrow \text { whole brain homogenates } \\
\text { IB: No } \Delta \text { Hsc } 70 \text { whole brain homogenates }\end{array}$ & [72] \\
\hline Hsp90 & $\mathrm{R} 6 / 2$ & $\begin{array}{l}\text { IB: No } \Delta \text { Hsp90 whole brain homogenates } \\
\text { IB: No } \Delta \text { Hsp84 whole brain homogenates }\end{array}$ & [72] \\
\hline Hsp105 & - & - & - \\
\hline
\end{tabular}

These results are from immunoblot (IB), or liquid chromatography coupled with quantitative mass spectrometry (LC-MS) of affected CNS regions 


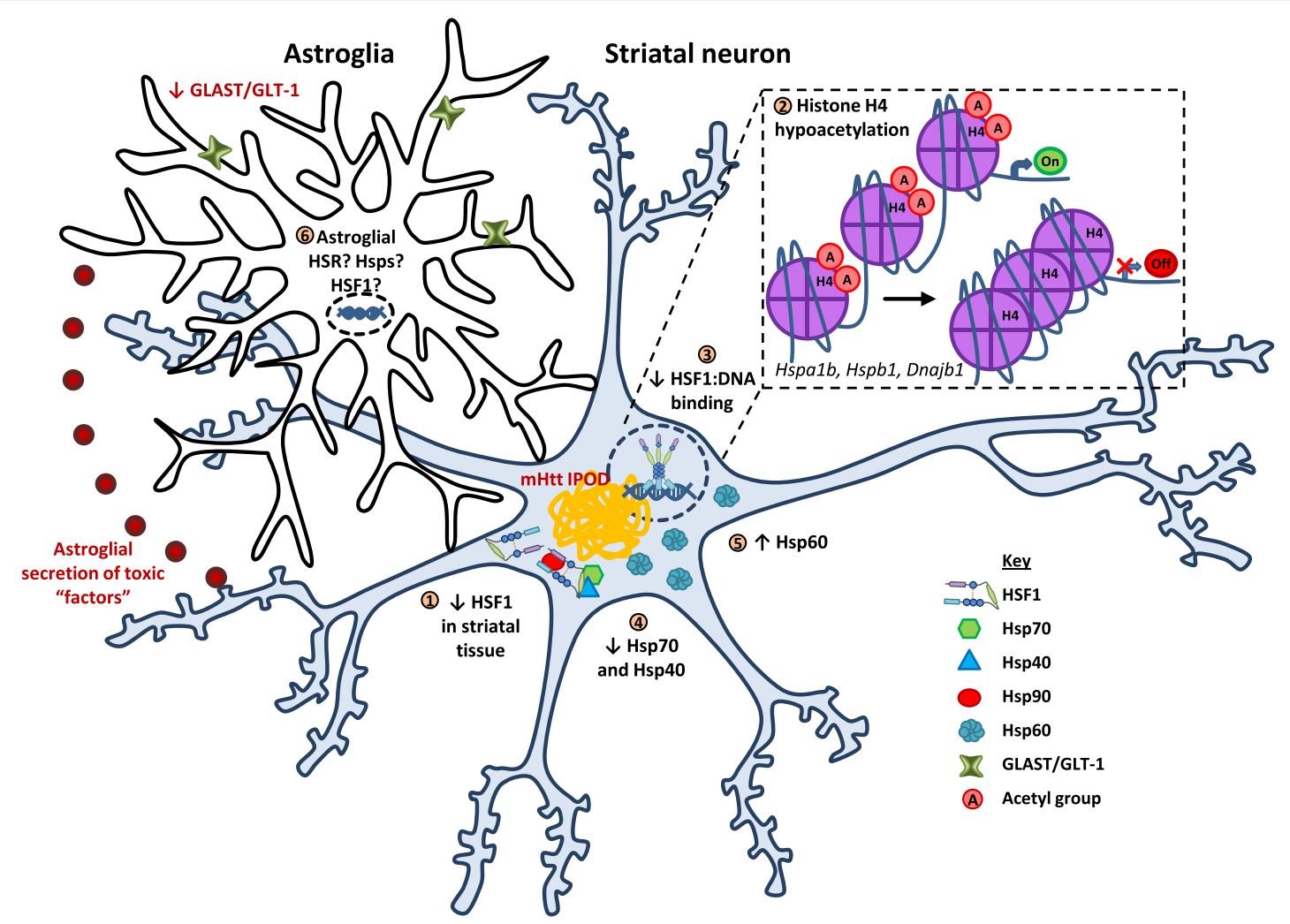

Fig. 3 Proposed summary of changes in the HSR and its components in polyQ-expanded Htt over-expression models of HD. Huntington's disease onset and progression into late stage is dependent on the molecular pathologies developed in striatal neurons (e.g. formation of polyQexpanded Htt aggregates or IPODs) and astroglia (e.g. decline in GLAST/GLT-1 expression and the secretion of unidentified toxic "factors"). The susceptibility of striatal neurons to degeneration from HD-associated stresses could be the result of a polyQ-expanded Htt-mediated attenuation of the HSR. Over-expression of polyQ-expanded Htt in CNS tissues results in a (1) reduction in HSF1 levels. (2) Histone H4 acetylation has been shown to be a strong promoter of HSF1 binding to DNA of target genes. However, hypoacetylation of histone H4 at HSF1 targets (e.g. Hspa1b, Hspb1, and Dnajb1) with disease progression can explain (3) the decrease in HSF1 binding to DNA observed in polyQ-expanded Htt expressing striatal neurons. (4) HD disease progression is also associated with a decline in Hsp70 and Hsp40 family members and (5) a striatal-specific increase in Hsp60. (6) There have been few investigations regarding HSF1 activation and DNA-binding in astroglia. Therefore, the capacity of polyQ-expanded Htt over-expressing astroglia to activate HSF1 and induce an HSR is currently unknown

kinase and Fbxw7 Fbox protein (an E3 ubiquitin ligase) in the enhanced degradation of HSF1 in cells expressing polyQ-expanded Htt [74]. The proposed model suggests that polyQ-expanded Htt up-regulates CK2 $\alpha$ ' kinase expression and increases the phosphorylation of HSF1 at S303 and S307. This in turn recruits Fbxw7, which ubiquitinylates phospho-HSF1 targeting it for degradation by the ubiquitin proteasome system [74]. Enhanced degradation of HSF1 by the proteasome has also been implicated in a mouse model and human post-mortem tissues of $\alpha$-synucleinopathies, whereby elevated levels of the ubiquitin ligase, NEDD4, ubiquitinates HSF1 for degradation [25]. Whilst expression of $\mathrm{Htt}^{111 \mathrm{Q}}$ is not sufficient to induce HSF1 activation in cerebellar granule cells, heat shock does result in activated (hyperphosphorylated) HSF1 trimers accumulating in the cell nucleus $[32,71]$. Similarly, HSF1 dissociation from Hsp90, hyperphosphorylation, and nuclear translocation are not impaired in HD mice upon treatment with the Hsp90 inhibitor NVP-HSP990, which is able to penetrate into the brain [71]. Therefore, there is a reduction in total HSF1 levels in the striatum; however, HSF1 can become hyperphosphorylated and translocate into the nucleus in HD models.

With regard to the DNA binding capacity of HSF1 in HD models, evidence suggests that the expression of polyQ-expanded Htt attenuates HSF1 binding to DNA in striatal cells [73]. Genome-wide chromatin immunoprecipitation (ChIP) experiments demonstrated that in primary striatal neurons expressing $\mathrm{Htt}^{111 \mathrm{Q}}$, HSF1 is only capable of binding $39 \%$ of its target genes after heat shock (1159 bound genes) compared to cells expressing $\mathrm{Htt}^{7 \mathrm{Q}}$ (2943 bound genes) [73]. Microarray data show that the reduced HSF1 binding to DNA in heat shocked cells expressing $\mathrm{Htt}^{111 \mathrm{Q}}$ corresponds with a decline in the transcription of several Hsps (Dndjb5, Dnajb12 and Hspb6). Furthermore, mRNA levels of Hsp70, Hsp40 and Hsp25 were reduced in the cerebral cortices of HD mouse 
models compared to controls following treatment with NVP-HSP990 [75]. Therefore, since HSF1 activation appears to be unimpaired, low levels of HSF1 and its compromised ability to bind DNA could account for the observed inability of cells expressing polyQ-expanded Htt to elicit an HSR. This dysregulation of chaperone gene expression likely plays a key role in the pathology of HD.

Altered chromatin architecture in HD may explain the reduced capacity of HSF1 to bind to target genes in striatal neurons under stress [75-78]. Quantitative PCR coupled with ChIP analysis after NVP-HSP990 (Hsp90 inhibitor) treatment demonstrated significant hypoacetylation of histone $\mathrm{H} 4$ at Hspalb, Hspb1, Dnajb1 genes in $\mathrm{Htt}^{111 \mathrm{Q}}$ expressing primary striatal neurons compared to $\mathrm{Htt}^{7 \mathrm{Q}}$ [75]. Hypoacetylation of these Hsp genes may change the chromatin landscape sufficiently to interfere with HSF1 binding to DNA (Fig. 3). Stress-inducible binding of HSF1 to DNA is associated with histone acetylation, H3K4 trimethylation, RNA polymerase II and other co-activators [77]. Furthermore, tetra-acetyl histone $\mathrm{H} 4$ has previously been suggested to be a strong modulator of HSF1 binding to DNA [77]. Therefore, it follows that histone $\mathrm{H} 4$ hypoacetylation in HD models may reduce chromatin accessibility of HSF1 at heat shock genes, consequently impairing the HSR.

At the tissue level, there are several studies that have investigated Hsp expression, and therefore HSR activation, in affected and non-affected tissues in mouse models of HD (Table 1). Immunoblot analysis of whole brain or spinal cord homogenates from HD mice have shown that overall there is no change in the total protein levels of the sHsps Hsp25 or $\alpha$ B-crystallin ( $\alpha$ B-c, HSPB5) or Hsp90 family members compared to mice expressing nonpathogenic Htt $[72,79]$. Whole tissue homogenates from HD mice showed a reduction in HSF1, Hsp70, and two Hsp40 family members (Hdj1 and Hdj2; Fig. 3) [32, 72]. Conversely, striatal homogenates from HD mice were found to have a 4-fold increase in Hsp60 levels compared to control mice [80]. A lack of immunohistochemistry in these studies makes it impossible to determine (i) where changes occur at the cellular level and (ii), whether small cell populations or specific cell-types induce an HSR, which is undetectable in bulk cell analyses. Employing immunohistochemistry in parallel to this work, or more powerful omics-based single-cell analyses, such as the proteomics approach undertaken by Sharma et al. [81], has the potential to resolve cell-type and brain-region specific differences in the presence or absence of disease. In this way, cell-type specific differences in the ability to induce a pro-survival HSR will be identified.

\section{The role of glial cells in HD}

There is evidence that the onset and progression of HD is both cell-autonomous and non-cell autonomous. One study showed that a transgenic mouse with panneuronal expression of $\mathrm{Htt}^{103 \mathrm{Q}}$ developed pathologies associated with end-stage disease, including astrogliosis, motor deficits and neurodegeneration [82, 83]. However, when $\mathrm{Htt}^{103 \mathrm{Q}}$ expression was restricted to either striatal neurons or cortical pyramidal neurons, pathologies associated with end-stage disease did not develop despite these cells having nuclear polyQ-expanded Htt aggregates and alterations in NMDA receptor function [82, 83]. These studies showed for the first time that HD pathogenesis and propagation depends on interactions between neuronal subtypes. Neuronastroglia interactions have also been implicated in the non-cell autonomous progression of HD. A study that investigated transgenic mice that expressed $\mathrm{Htt}^{98 \mathrm{Q}}$ in both neurons and astroglia observed that these mice displayed more severe neurological symptoms and earlier death compared to mice in which $\mathrm{Htt}^{98 \mathrm{Q}}$ expression was restricted to either neurons or astroglia alone [84]. Therefore, it seems likely that both neuron-neuron and neuron-astroglia interactions are responsible for the onset and progression of HD.

The combination of molecular pathologies that develop in neurons and astroglia work in tandem to progress HD (Fig. 3). However, the mechanisms that underlie astroglial-mediated toxicity in $\mathrm{HD}$ are only partially understood. Astroglia expressing polyQexpanded Htt secrete neurotoxic factors and decrease the expression of the glutamate transporters, GLAST and GLT-1 [85-87]. Indeed, polyQ-expanded Httexpressing astroglia have been shown to increase the vulnerability of striatal and cortical neurons in coculture to excitotoxic stresses [88]. Conversely, in coculture experiments, astrocytes expressing nonpathogenic $\mathrm{Htt}^{23 \mathrm{Q}}$ protected $78 \%$ of the $\mathrm{Htt}^{130 \mathrm{Q}}$-expressing cortical neurons from glutamate toxicity [88]. Furthermore, conditioned medium derived from WT astroglial cultures protects $\mathrm{Htt}^{111 \mathrm{Q}}$-expressing striatal neuronal progenitor cells from neurotoxic insults (e.g. $\mathrm{H}_{2} \mathrm{O}_{2}$, glutamate, 3-nitropropionic acid) [89].

With respect to neurotoxic factors secreted by astroglia, an elegant study by Liddelow et al. [86], demonstrated that pro-inflammatory microglia can activate a neurotoxic phenotype in astroglia (defined in the work as A1 astroglia). They showed that A1 astrocyte formation is a pathological response of the CNS in mice treated with systemic injections of lipopolysaccharide and acute CNS injury, and in patients with NDs [86]. The proportion of neurotoxic (A1) astroglia in the caudate nucleus of HD patients was significantly greater than in controls $(60 \%$ in HD tissue compared to $25 \%$ in the control) [86]. Furthermore, qPCR of A1 astroglia-associated transcripts showed a 60-fold increase in the caudate nucleus of 
HD patients compared to controls [86]. Thus, cell-cell interactions and dysfunctions of striatal or cortical pyramidal neurons and astroglia are likely to work synergistically to progress HD into late-stages. Therefore, it is important to maintain astrocytes in the striatum in a healthy and neurotrophic condition to minimize neurodegeneration in the striatum. The focus of research investigating pro-survival mechanisms and the proteostasis network in HD has thus far been predominantly focused on striatal neurons. However, considering accumulating evidence that implicates astroglia in the pathogenesis of $\mathrm{HD}$, it is relevant to also investigate these pathways in astroglia.

\section{The HSR in striatal astrocytes}

Studies investigating HSR-inducing compounds have provided valuable insights into the capacity of different cell populations to induce an HSR in the absence of the expression of polyQ-expanded Htt. Primary striatal astrocytes derived from WT mice showed a stronger induction of the HSR compared to striatal projection neurons after treatment with the Hsp90 inhibitor, NVPHSP990: treated striatal astroglia showed an 18-fold increase in Hsp70 and 4-fold increase in Hsp25 mRNA levels [90]. In contrast, NVP-HSP990 treated striatal projection neurons only showed an 8-fold increase in Hsp70, 3-fold increase in Hsp40, and no change in Hsp25 mRNA levels [90]. In the vehicle treated mice, there were no significant differences compared to nontreated mice in the synthesis of any of the Hsp mRNAs investigated (Hsp70, Hsp40, Hsp90 or HSF1), with the exception of Hsp25, which showed a 7-fold increase in astroglia compared to striatal projection neurons [90]. Together these findings suggest that, in the absence of polyQ-expanded $\mathrm{Htt}$ expression, striatal astroglia are "pre-loaded" with greater levels of Hsp25 mRNA and can induce a stronger HSR compared to striatal projection neurons.

The size and frequency of formation of polyQ-expanded $\mathrm{Htt}$ inclusions varies across different cell-types in the CNS. Striatal and frontal cortex glial fibrillary acidic protein (GFAP)-positive astroglia demonstrated a significant reduction in the size and the proportion of cells with $\mathrm{Htt}^{210 \mathrm{Q}}$ inclusions compared to neurons in these CNS regions in a mouse model of HD [91]. This difference was attributed to a possible increase in proteostasis network components (including heat shock proteins) in reactive astroglia. However, there is insufficient evidence from models of HD, with regards to the Hsp content of striatal astroglia, to draw relationships between inclusion size and number and proteostasis capacity of striatal astroglia (Fig. 3).

Determining mechanisms that maintain astroglia in a healthy and neurotrophic state should be a priority in future HD research, given that polyQ-expanded $\mathrm{Htt}$ expression decreases the levels of glutamate transporters and induces a neurotoxic phenotype of astroglia. Indeed, a recent study demonstrated that the over-expression of the sHsp, $\alpha \mathrm{B}-\mathrm{c}$, in astroglia ameliorates the pathologies associated with HD in transgenic mice that express fulllength $\mathrm{Htt}^{97 \mathrm{Q}}$ [92]. Over-expression of $\alpha \mathrm{B}-\mathrm{c}$ in astroglia significantly reduced the number of large $(>1 \mu \mathrm{m})$ $\mathrm{Htt}^{97 \mathrm{Q}}$ inclusions in the striatum and cortex, and resulted in a $14 \%$ increase in the number of NeuN-positive neurons in the striatum [92]. This provides an elegant example of how increasing Hsps in astroglia can ameliorate HD neuropathologies in a non-cell autonomous manner and provides support for increased investigation into the HSR in astroglia in the context of HD.

\section{Summary of the HSR in HD}

It has been demonstrated using a range of cell and animal models of HD that striatal neurons do not sense or respond to polyQ-expanded $\mathrm{Htt}$ expression by upregulating Hsps. Moreover, striatal neurons expressing polyQ-expanded $\mathrm{Htt}$ have an attenuated capacity to induce an HSR after heat shock. This could be due to decreased levels of HSF1 in striatal tissue observed in HD models. In addition, the altered chromatin landscape caused by histone $\mathrm{H} 4$ hypoacetylation at Hsp genes observed in a HD mouse model, may also lead to decreased binding of HSF1 to DNA, and down-regulation of Hsp70 and Hsp40. In the absence of polyQ-expanded $\mathrm{Htt}$ expression, striatal astroglia, compared to striatal projection neurons, have greater levels of Hsp25 mRNA and can induce a stronger HSR. However, the effect of polyQ-expanded Htt on HSR induction in astroglia remains to be elucidated.

Previous research has demonstrated that a variety of Hsps can inhibit polyQ-expanded Htt protein aggregation. However, the affected neurons in HD appear not to sense the initial stages of pathogenic protein misfolding as a cellular stress and therefore do not activate an HSR. As the neurons and surrounding astroglia in the CNS appear to be incapable of activating an HSR in the context of HD, therapeutics that can induce Hsp expression in early stages of disease may prove beneficial.

\section{Amyotrophic lateral sclerosis}

Amyotrophic lateral sclerosis is characterized by a loss of motor neurons in the primary motor cortex, corticospinal tracts, brainstem and spinal cord. Only $5-10 \%$ of ALS cases are familial (fALS) and some of these arise from mutations in one of 13 (or more) genes leading to the expression of aberrant aggregation-prone proteins. Mutations in SOD1 (copper/zinc ion-binding superoxide dismutase), FUS (fused in sarcoma), TDP-43 (TAR DNA binding protein), CCNF (cyclin F) [93], OPTN (optineurin), ANG (angiogenin, ribonuclease, RNase A family, 
5), UBQLN2 (ubiquitin-like ubiquilin2), and others, as well as repeat expansions in C9ORF72 (chromosome 9 open reading frame 72), are all associated with fALS (recently reviewed by $[94,95]$ ). The remaining $90-95 \%$ of ALS cases are idiopathic and sporadic. In ALS, motor neurons are selectively susceptible to degeneration as a consequence of mutant ALS-associated protein expression, despite the ubiquitous presence of these same mutant forms in neuronal and non-neuronal cells [96]. Motor neurons have functional and morphological characteristics that may make them particularly vulnerable to toxic protein misfolding and aggregation, neuroinflammation, excitotoxic insults, oxidative damage and subsequent degeneration in ALS [96]. For example, motor neurons have a high metabolic load, high energy demands, long axons, and rely on rapid signaling of neurotransmitters to other neurons and muscle tissue by axonal transport. Malfunction of each of these characteristics of motor neurons have been associated with ALS pathology (for reviews see [97-99]). In addition, recent findings have shown that multiple housekeeping and stress-response pathways involved in maintaining proteostasis (e.g. the ubiquitin proteasome system and endoplasmic reticulum unfolded protein response) are dysregulated in ALS-affected motor neurons, which would further exacerbate their degeneration [96, 100105]. However, it remains to be established whether affected cell-types in the CNS can induce an HSR as a result of pathogenic protein aggregation associated with ALS as a protective response to this chronic proteotoxic stress.

\section{The HSR in motor neurons}

Motor neurons may have a relatively high threshold for HSR induction compared to surrounding non-neuronal cells. Batulan et al. [53] investigated the endogenous expression of HSF1 in motor neurons and their capacity to activate the HSR. In these studies, immunohistochemistry of motor neurons in spinal cord cultures demonstrated the presence of HSF1, but not Hsp70, in these cells. The capacity of motor neurons to induce an HSR was assessed following heat shock $\left(42{ }^{\circ} \mathrm{C}\right.$ for $1 \mathrm{~h}$ ) by monitoring the stress-inducible expression of an Hsp70 promoter driven EGFP construct. The lack of EGFP fluorescence in motor neurons after heat shock suggested that HSF1 was not activated and thus did not bind to the HSE used in this reporter construct [53]. Other studies have also shown that spinal cord motor neurons in situ fail to transcribe and express Hsp70 following heat shock $[58,106]$. However, it is not clear from this work whether HSF1 was (i) not activated and therefore not capable of binding DNA and/or (ii) not present at sufficient levels in these cells to induce an HSR.
To determine which of these possibilities was responsible for these observations, WT HSF1 $\left(\mathrm{HSF} 1^{\mathrm{WT}}\right)$ and a constitutively active mutant of HSF1 $\left(\mathrm{HSF}^{+}\right)$were overexpressed in primary murine motor neurons [53]. Simply increasing the level of $\mathrm{HSF} 1^{\mathrm{WT}}$ in cells was not sufficient to enhance their capacity to express Hsp70 [53]. Conversely, over-expression of $\mathrm{HSF}^{+}$resulted in an up-regulation of Hsp70, Hsp40, and Hsp25 levels in $96.1 \pm 3.4 \%, 100 \pm 0 \%$, and $14.6 \pm 7.3 \%$ in motor neurons, respectively $[53,107]$. Furthermore, expression of $\mathrm{HSF}^{+}$in motor neurons expressing pathogenic SOD1 ${ }^{\text {G93A }}$ significantly reduced the formation of inclusions and conferred cytoprotection, compared to HSF1 ${ }^{\text {WT }}$ [107]. Together, these findings suggest that the attenuated capacity of motor neurons to induce an HSR in the context of heat shock is due to their inability to activate HSF1, not insufficient levels of HSF1 in these cells (Fig. 4).

The over expression and aggregation of mutant SOD1 (mSOD1) in mouse models may not be sufficient to induce an HSR in motor neurons. Primary murine motor neurons expressing mSOD1 demonstrate no change in expression levels of Hsp70, Hsp105, Hsp90, Hsp60, or Hsp40 compared to those expressing SOD1 ${ }^{\text {WT }}$ and nontransgenic control motor neurons (Table 2). Furthermore, a reduction in Hsp105 levels was observed in spinal cord tissue homogenates of SOD $1^{\text {G93A }}$ mice [108]. Hsp105 is a chaperone expressed in neurons and glia- in the CNS and can inhibit the aggregation of mSOD1 in cell-based models [108]. Therefore, the decline in Hsp105 expression, combined with the inability of rodent motor neurons to up-regulate Hsp70, Hsp90, Hsp60, or Hsp40, suggests that the HSR is either unable to be activated or is impaired in these models of ALS (Fig. 4).

In the absence of disease, the endogenous and constitutive expression of Hsp27 in motor neurons of the spinal cord plays an important role in the housekeeping of proteostasis. Hsp27 is a well characterized molecular chaperone that also has potent anti-apoptotic functions [109]. Hsp27 can inhibit the release of mitochondrial cytochrome c and associate with Daxx, thereby inhibiting a motor neuron-specific apoptosis pathway mediated by Fas-Ask1-p38 [109-112]. However, in transgenic mouse models Hsp25 levels become dysregulated and decline in motor neurons during ALS progression (Table 2). Studies have shown that pre-symptomatic mSOD1 mice have Hsp25 levels comparable to age-matched controls $[113,114]$. However, immediately prior to the onset of disease symptoms, Hsp25 levels decline in spinal cord motor neurons as demonstrated by immunohistochemistry of spinal cord sections $[113,114]$. In contrast, by the late stages of the disease, both Hsp25 and $\alpha B-c$ are upregulated in spinal cord astroglia, a finding consistent in numerous studies [79, 113-116]. Future research could 


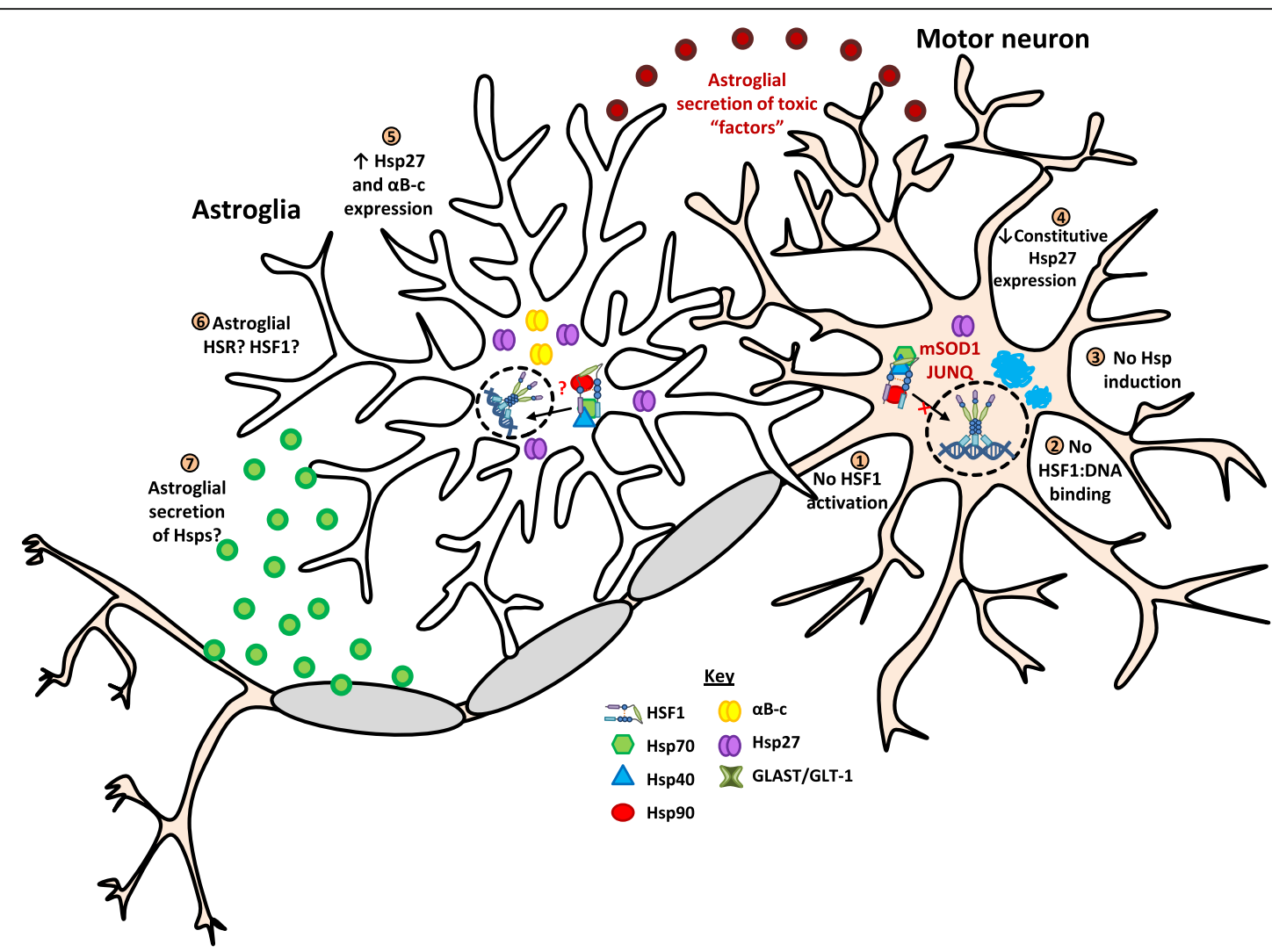

Fig. 4 Proposed mechanism of the HSR and its components in motor neurons and astroglia of mSOD1 over-expressing models of ALS. Motor neuron disease initiation and progression is dependent on the molecular pathologies developed in motor neurons (e.g. formation of mSOD1 aggregates or JUNQ) and astroglia (e.g. secretion of unidentified toxic "factors"). The susceptibility of motor neurons to degeneration is likely due to an inability of motor neurons and astroglia to induce a cytoprotective HSR in response to increasing quantities of misfolded proteins (e.g. mSOD1). (1 and 2) HSF1 in motor neurons has a relatively high threshold for activation and the over-expression of mSOD1 and subsequent molecular pathologies do not activate HSF1 nor induce HSF1 binding to DNA. (3) There is no detectable basal expression or up-regulation of Hsps in mSOD1 over-expressing motor neurons, with the exception of (4) Hsp27, which gradually declines with disease progression. (5) Astroglia in mSOD1 over-expressing mice have increased amounts of Hsp27 and aB-c with disease progression; however, the levels of other Hsps are not changed. (6) There have been few investigations regarding HSF1 activation and DNA-binding in astroglia in the context of ALS. Therefore, the capacity of mSOD1 over-expressing astroglia to activate HSF1 and induce an HSR remains unknown. (7) There is increasing evidence that extracellular vesicles containing Hsps are secreted by astroglia, and these vesicles are endocytosed by motor neurons and facilitate transfer of Hsps

address whether this decline in Hsp25 in mSOD1 expressing motor neurons correlates with an increase in Hsp25 sequestered in insoluble protein deposits. This could be achieved by immunoblot analysis of soluble and insoluble protein fractions and immunohistochemistry. The decrease in Hsp25 in motor neurons during the later stages of ALS in these transgenic mouse models may increase their susceptibility to neurodegeneration as a consequence of toxic protein accumulation and other ALS-related stresses (Fig. 4).

With regards to ALS in humans, immunohistochemistry of human motor neurons in cervical spinal cord sections obtained at autopsy showed no change in Hsp70 or Hsp27 levels compared to age-matched controls [53]. The combined evidence suggests that the toxicity of mSOD1 in spinal cord motor neurons is not sufficient to elicit the stress-inducible expression of Hsps in rodents or humans. In contrast, Hsp70 (but not Hsp27) immunoreactivity was occasionally observed to be higher in neighboring glial cells in fALS or sporadic ALS patients [53]. This suggests that astroglia in humans and rodents are capable of up-regulating certain Hsps in response to stresses associated with ALS. This further supports the hypothesis that motor neurons intrinsically have a high threshold for induction of the HSR and suggests that misfolded mSOD1 can go undetected by this inducible arm of the proteostasis network in these cells.

There is a lack of diversity in the models that have been used in work investigating the HSR in association with ALS. Data regarding neuronal and glial Hsp expression in ALS is derived primarily from mSOD1 rodent models, with the exception of one study that used the TDP$43^{\mathrm{WT} \times \mathrm{Q} 331 \mathrm{~K}}$ transgenic mouse model of ALS [117]. Therefore, it remains to be determined whether these findings 
Table 2 List of Hsps and whether their expression is up-regulated $(\uparrow)$, down-regulated $(\downarrow)$, or not changed (No $\Delta$ ) in rodent models of motor neuron disease at the late-stage of disease compared to age-matched transgenic WT or non-transgenic mouse controls

\begin{tabular}{|c|c|c|c|}
\hline Hsps & Transgenic disease models & Tissue or cell type & Reference \\
\hline \multirow[t]{2}{*}{ HSF1 } & TDP-43 ${ }^{W T \times Q 331 K}$ & IB: $\downarrow$ spinal cord tissue homogenates & [117] \\
\hline & SOD $1^{\text {G93A }}$ & IB: $\downarrow$ spinal cord tissue homogenates & [174] \\
\hline \multirow[t]{3}{*}{ aB-c (HSPB5) } & SOD1 $1^{\mathrm{L} 126 Z}$ & $\begin{array}{l}\text { IHC: } \uparrow \text { spinal cord astroglia } \\
\text { IHC: } \downarrow \text { spinal cord oligodendrocytes }\end{array}$ & [115] \\
\hline & SOD $1^{\mathrm{G} 93 \mathrm{~A}}$ & IHC: $\uparrow$ spinal cord astroglia & {$[116,175]$} \\
\hline & $\mathrm{SOD} 1^{\mathrm{G} 37 \mathrm{R}}$ & $\mathbb{H C}: \uparrow$ spinal cord astroglia & [116] \\
\hline Hsp22 (HSPB8) & SOD $1^{\mathrm{G} 93 \mathrm{~A}}$ & IHC: $\uparrow$ spinal cord motor neurons & {$[176,177]$} \\
\hline \multirow[t]{4}{*}{ Hsp25 (HSPB1) } & SOD $1^{\text {G93A }}$ & $\begin{array}{l}\text { IHC: } \uparrow \text { spinal cord astroglia } \\
\text { IHC: } \downarrow \text { spinal cord oligodendrocytes }\end{array}$ & {$[53,113,114,116]$} \\
\hline & $\mathrm{SOD} 1^{\mathrm{G} 37 \mathrm{R}}$ & $\begin{array}{l}\text { IHC: } \uparrow \text { astroglia in the inferior colliculus, cerebellar } \\
\text { white matter, brain stem, spinal cord }\end{array}$ & [79] \\
\hline & SOD1 $1^{L 126 Z}$ & IHC: $\downarrow$ spinal cord motor neurons & [115] \\
\hline & $\mathrm{SOD} 1^{\mathrm{G} 93 \mathrm{~A}} \mathrm{SOD} 1^{\mathrm{G} 85 \mathrm{R}}, \mathrm{SOD} 1^{\mathrm{G} 37 \mathrm{R}}, \mathrm{SOD} 1^{\mathrm{H} 46 \mathrm{R} / \mathrm{H} 48 \mathrm{Q}}$ & $\begin{array}{l}\text { IHC: } \uparrow \text { spinal cord astroglia } \\
\mathbb{H C}: \uparrow \text { spinal cord undefined neurons }\end{array}$ & {$[178]$} \\
\hline \multirow[t]{3}{*}{ Hsp40 } & SOD $1^{\mathrm{G} 93 \mathrm{~A}}$ & IHC: No $\triangle$ spinal cord & [79] \\
\hline & $\mathrm{SOD} 1^{\mathrm{G} 93 \mathrm{~A}} \mathrm{SOD} 1^{\mathrm{G} 85 \mathrm{R}}, \mathrm{SOD} 1^{\mathrm{G} 37 \mathrm{R}}, \mathrm{SOD} 1^{\mathrm{H} 446 \mathrm{R} / \mathrm{H} 48 \mathrm{Q}}$ & IB: No $\Delta$ spinal cord tissue homogenates & {$[178]$} \\
\hline & $T D P-43^{W T \times Q 331 K}$ & IB: No $\Delta$ spinal cord tissue homogenates & [117] \\
\hline \multirow[t]{2}{*}{ Hsp60 } & SOD $1^{\text {G93A }}$ & IHC: No $\triangle$ spinal cord & [79] \\
\hline & $\mathrm{SOD} 1^{\mathrm{G} 93 \mathrm{~A}} \mathrm{SOD} 1^{\mathrm{G} 85 \mathrm{R}}, \mathrm{SOD} 1^{\mathrm{G} 37 \mathrm{R}}, \mathrm{SOD} 1^{\mathrm{H} 46 \mathrm{R} / \mathrm{H} 48 \mathrm{Q}}$ & IB: No $\Delta$ spinal cord tissue homogenates & {$[178]$} \\
\hline \multirow[t]{3}{*}{ Hsp70 } & $\mathrm{SOD} 1^{\mathrm{G} 93 \mathrm{~A}} \mathrm{SOD} 1^{\mathrm{G} 85 \mathrm{R}}, \mathrm{SOD} 1^{\mathrm{G} 37 \mathrm{R}}, \mathrm{SOD} 1^{\mathrm{H} 46 \mathrm{R} / \mathrm{H} 48 \mathrm{Q}}$ & IB: No $\Delta$ spinal cord tissue homogenates & {$[53,79,115,178]$} \\
\hline & SOD $1^{\text {G93A }}$ & IHC: $\uparrow$ "sick-appearing" spinal cord motor neurons & [179] \\
\hline & SOD $1^{\mathrm{G} 85 \mathrm{R}}$ & IB: $\uparrow$ spinal cord tissue homogenates & [145] \\
\hline \multirow[t]{2}{*}{ Hsp90 } & SOD $1^{G 93 A}$ & IHC: No $\triangle$ spinal cord & [79] \\
\hline & $\mathrm{SOD} 1^{\mathrm{G} 93 \mathrm{~A}} \mathrm{SOD} 1^{\mathrm{G} 85 \mathrm{R}}, \mathrm{SOD} 1^{\mathrm{G} 37 \mathrm{R}}, \mathrm{SOD} 1^{\mathrm{H} 46 \mathrm{R} / \mathrm{H} 48 \mathrm{Q}}$ & IB: No $\triangle$ spinal cord tissue homogenates & [178] \\
\hline Hsp105 & SOD $1^{\mathrm{G} 93 \mathrm{~A}}$ & $\mid \mathrm{B}: \downarrow$ in spinal cord tissue homogenates & {$[108]$} \\
\hline
\end{tabular}

These results are from immunoblot (IB) or immunohistochemical (IHC) staining and microscopy of different CNS regions

also apply to other fALS-associated mutations (e.g. FUS). This is of particular relevance if each aggregation-prone protein engages a specific set of Hsps, as has been previously proposed [118]. Therefore, additional research is required in other rodent models of ALS to advance our understanding of the HSR in this disease.

\section{The role of glial cells in ALS}

There is strong evidence that ALS can be characterized as a non-cell autonomous disease [99, 119]. As such, ALS initiation and progression depends on both the molecular pathologies developed within motor neurons, and the subsequent reactivity of surrounding non-neuronal cell populations such as astroglia and microglia. For example, transgenic mice expressing $\mathrm{SOD} 1^{\mathrm{G} 37 \mathrm{R}}$ specifically in motor neurons in the ventral horn of spinal cords remained healthy for up to 1.5 years of age compared to mice that ubiquitously express this mSOD1 isoform, which die at 4 months of age $[120,121]$. Moreover, knock out of SOD $1^{\mathrm{G} 37 \mathrm{R}}$ expression in motor and dorsal root ganglion neuron progenitors of transgenic mice results in an 18 day delay to disease onset and 31 day delay to early disease progression compared to controls [122]. Together, these findings demonstrate that mSOD1 expression in motor neurons plays a role in early disease initiation and mSOD1 expression in other cells is required for disease progression. In support of this, selective deletion of SOD $1^{\mathrm{G} 37 \mathrm{R}}$ expression from GFAP-positive spinal cord astroglia or cluster of differentiation molecule 11B (CD11b)-positive microglia did not slow disease onset or early disease progression, but significantly delayed late disease progression resulting in an overall extension of survival by 60 and 99 days, respectively [122, 123]. These two studies demonstrate that mSOD1 expression in astroglia and microglia plays a significant role in late disease progression and overall survival. This work and the work of many others emphasizes the importance of astroglia and microglia in the pathogenic cascade associated with ALS (for in-depth reviews examining the non-cellautonomous nature of ALS see [99, 119, 124]).

The non-cell-autonomous progression of ALS by glial cells has also recently been demonstrated in a mutant 
TDP-43 model of ALS [125]. In a TDP-43 ${ }^{\text {Q331K }}$ expressing transgenic mouse model of ALS, cre recombinase excision of the TDP- $43^{\mathrm{Q} 331 \mathrm{~K}}$ transgene from motor neurons completely rescued motor neuron death [125]. However, despite the increase in motor neuron survival, there was no significant difference in the number of degenerating axons and neuromuscular junctions or glialmediated neuroinflammation in end-stage disease mice when the TDP- $43^{\mathrm{Q} 331 \mathrm{~K}}$ transgene was excised in motor neurons [125]. These findings are supported by research that showed that astroglial-specific expression of TDP $-43^{\mathrm{M} 337 \mathrm{~V}}$ in rats results in the death of spinal cord motor neurons and denervation of skeletal muscles [126]. One proposed mechanism for the neurotoxicity of astroglia in mutant TDP-43 expressing models is that neurotrophic genes are suppressed and neurotoxic genes are up-regulated (e.g. LCN2 and CHI3L1) [127]. Combined, these studies suggest that the expression of mutant TDP-43 in astroglia is sufficient to cause non-cell-autonomous death of motor neurons. Furthermore, the non-cell-autonomous progression of ALS is not confined to mSOD1-expressing mouse models, but may represent a generic mode of ALS progression.

The ubiquitous expression of mutant ALS-associated protein in the CNS may not alone facilitate the transition of astroglia from a neurotrophic to neurotoxic phenotype in ALS. Co-culture with A1 astrocytes induces the rapid death of a range of neurons, including spinal cord $\alpha$-motor neurons [86]. Interestingly, there was a significant increase in the proportion of A1 astroglia in the motor cortex of patients with ALS (40\% of ALS astroglia were A1 compared to $15 \%$ in controls) [86]. Likewise, there was a 60-fold increase in A1-related transcripts in the motor cortex of ALS patients compared to controls [86]. The mechanism by which these A1 astrocytes induce toxicity was proposed to be through the secretion of a 'toxic factor' [86]. Other studies have also suggested that mSOD1-expressing astrocytes release a soluble 'toxic factor', which significantly reduces the viability of motor neurons in co-culture [128-131]. The identity of this neurotoxic factor is currently unknown and additional research is required to determine its mode of action. In any case, it is important to consider cytoprotective mechanisms that maintain the neurotrophic functions of glia in ALS, such as the HSR leading to Hsp expression.

\section{The HSR in astroglia}

It is generally regarded that astroglia are capable of activating an HSR in response to stress, including whole animal hyperthermia [51,57-59]. In the context of ALS, astroglia have higher levels of the sHsps, $\alpha B-c$ and Hsp25, compared to WT controls at the end-stage of disease, but not Hsp90, Hsp70, Hsp60 or Hsp40 (Table 2, Fig. 4). Interestingly, these findings suggest that the over-expression of unstable and misfolded mSOD1 species in the CNS fails to activate the HSR. Moreover, the expression of sHsps and other Hsp families may not be under the same transcriptional and translational controls.

In astroglia, there is a scarcity of published work investigating HSF1-activation and HSR induction at the molecular level using biochemical techniques (Fig. 4). However, the discord between sHsps being up-regulated and other Hsps not being affected in astroglia in the context of ALS suggests that there are additional layers of regulation of the HSR in these cells that are either HSF1-mediated or post-translational. In recent work, Zheng et al. [28] hypothesized that the phosphorylation of HSF1 at serine and threonine residues serves to finetune HSF1 transcription at promoter regions, rather than acting solely as an on/off switch. Thus, HSF1 phosphorylation could serve to regulate the kinetics and magnitude of the HSR in a cell-type dependent manner. Additional unidentified mechanisms of HSF1 regulation, including those that are cell-type specific, could explain the complete absence of HSR induction in motor neurons compared to astroglia in $\mathrm{mSOD} 1$-expressing transgenic mice. In fact, the HSF1-mediated HSR in the different cell-types that comprise the CNS is likely to be much more complex than our current models of HSR induction and attenuation (Fig. 2), which are based primarily on findings from Saccharomyces cerevisiae, Drosophila melanogaster, cell-lines or studies using recombinant human HSF1 in solution [38, 132-134]. Future research should elucidate mechanisms of HSR induction in astroglia, particularly astroglia that are affected in the spinal cord in ALS.

Knowledge of the precise mechanism by which HSF1 mediates the induction of specific Hsps in astroglia is important as it may uncover new therapeutic targets for the rescue of motor neurons from degeneration associated with ALS progression. This knowledge could be harnessed to up-regulate specific sets of Hsps that have been shown to interact with aggregating proteins associated with ALS [118]. For example, Hsp70 and HspB8 interact with TDP-43 and Hsc70, Hsp70, DNAJB1, DNAJB2a/b, Hsp27, $\alpha \mathrm{B}-\mathrm{c}$, and HspB8 interact with SOD1 to prevent protein aggregation and decrease cytotoxicity [118]. It has been proposed that other Hsps are also likely to prevent the aggregation of TDP-43 and SOD1 since there are numerous 'non-canonical' members of the Hsp families that have not been tested for anti-aggregation or anti-apoptotic activities in these assays [118]. Up-regulation of cytoprotective Hsps in astroglia could maintain them in a healthy neurotrophic state to support motor neuronal viability and prevent 
conversion of astroglia to a neurotoxic (A1) phenotype. However, further research is needed to investigate mechanisms of HSF1-mediated HSR induction across different CNS cell-types in the presence and absence of disease-associated protein aggregation.

One mechanism by which astroglia may provide cytoprotection to motor neurons is through the exchange of extracellular vesicles containing Hsps [135]. Extracellular vesicles derived from chick spinal cord primary astroglial cultures following heat shock contain Hsp70 and Hsc70 [136]. In another study investigating glial-neuronal interactions, T98G glioma cells were shown to secrete Hsp70 into the culture medium and LA-N-5 neuroblastoma cells took up this Hsp70 [137]. The Hsp70 uptake increased the stress tolerance of the LA-N-5 cells to heat shock and staurosporine-induced apoptosis [137]. It would be interesting to extend on this work to investigate whether extracellular vesicles from more physiologically relevant cell-models (e.g. primary murine astroglia and motor neurons) also facilitate the trafficking of Hsps. The mechanisms of astroglial exocytosis and neuronal endocytosis used to traffic Hsps are also yet to be elucidated. This non-cell-autonomous mechanism(s) by which astroglia provide products of the HSR to neurons could be exploited to increase Hsp levels in motor neurons. This strategy could enhance the stress tolerance of motor neurons and decrease degeneration in the spinal cord in ALS (Fig. 4).

\section{Summary of the HSR in ALS}

Spinal cord motor neurons from primary cell or animal models of ALS are unable to activate HSF1 and hence lack a stress-induced up-regulation of Hsps. The levels of Hsp27 in motor neurons decline with disease progression. Motor neurons have an inherently high threshold for the activation of the HSR and the expression and accumulation of mSOD1 in the cell is not sufficient to activate the HSR. In contrast, spinal cord astroglia have elevated levels of $\alpha \mathrm{B}-\mathrm{c}$ and Hsp25 (rodent) or Hsp70 (human) at the end-stage of disease. However, the precise mechanisms by which these Hsps are up-regulated are unknown. Overall, there is a distinct lack of research into the HSR in spinal cord astroglia and its potential role in ALS.

Due to the non-cell-autonomous nature of ALS, future research should focus on maintaining affected spinal cord astroglia in a neurotrophic state to support motor neuron viability. Furthermore, investigation of Hsp70 (and other Hsp) transfer between astroglia and motor neurons could represent an exciting new mechanism for the development of therapeutics that target the proteostasis network in ALS.

\section{Studying the therapeutic effects of increasing HSR components}

The plaques and inclusions that are characteristic of ALS, HD and other NDs all share common morphological and biochemical features and this points to the highly related nature of these diseases [138, 139]. In addition, plaques and inclusion bodies are co-localized with various components of the proteostasis network, which may represent an irreversible sequestration and subsequent loss of function of these vital housekeeping components [140]. The sequestration of these chaperones, in conjunction with the possibility that toxic misfolded proteins are not sufficient to induce an HSR in the CNS, are likely to be important molecular mechanisms that lead to neurodegeneration in these diseases. However, there appears to be mechanistic differences in the way that these pathological proteins inhibit or evade detection by the HSR. In the case of Htt, there is evidence to suggest that the misfolded proteins themselves may directly impair mechanisms of the proteostasis network by changing the chromatin landscape (Fig. 3). The absence of a stress-induced up-regulation of Hsps in early disease allows the formation of toxic protein species, which precede a cascade of cellular dysfunctions in NDs. Therefore, in the absence of an HSR in affected neurons and surrounding glia in the CNS, boosting the HSR pharmacologically represents a promising therapeutic intervention for the treatment of these diseases at an early stage.

A significant amount of work has investigated the effects of over-expressing individual Hsps or activating an HSF1-mediated HSR in rodent models of NDs (for comprehensive reviews see $[9,36,140-144])$. Determining which of the HSR components are the most efficacious in preventing protein aggregation and subsequent neurotoxicity is an important step in elucidating targets for the development of therapeutics that ameliorate NDs. Over-expression of individual chaperones in mSOD1 mouse models of ALS has resulted in modest effects with regards to a reduction in the amount of insoluble protein and increased motor neuron survival (Table 3) [145-150]. However, this does not correlate with an increase in overall survival of the double transgenic animals (Table 3) [145-150]. Conversely, up-regulation of the HSR by treatment with withaferin A, celastrol or arimoclomol results in an increase in the number of surviving motor neurons and the lifespan of mSOD1 expressing mice [151-154]. This same trend was observed in mouse models of HD, whereby overexpression of HSJ1a and Hsp70 has no effect on overall survival but over-expression of an active mutant of HSF1 extended survival by 15 days (Table 4) [155]. The exceptions to this are DNAJB1, DNAJB6 and QBPHsc70 binding motif which, when over-expressed, were 
Table 3 The effect of the over-expression of Hsps and up-regulation of the HSR on the molecular pathologies developed in rodent models of MND

\begin{tabular}{|c|c|c|c|c|c|c|}
\hline $\begin{array}{l}\text { Transgenic model/ } \\
\text { Therapeutic compound }\end{array}$ & $\begin{array}{l}\text { MND } \\
\text { model }\end{array}$ & Increase in $\mathrm{Hsp}$ in $\mathrm{Tg}$ mouse & $\begin{array}{l}\text { Extended } \\
\text { lifespan }\end{array}$ & $\begin{array}{l}\% \uparrow / \downarrow \text { in surviving } \\
\text { motor neurons }\end{array}$ & $\begin{array}{l}\% \uparrow / \downarrow \text { in levels } \\
\text { of inclusions }\end{array}$ & References \\
\hline \multirow[t]{2}{*}{ Hsp27 Tg } & SOD1 ${ }^{\mathrm{G} 93 \mathrm{~A}}$ & $\begin{array}{l}\text { 40-fold } \uparrow \text { spinal cord } \\
25 \text {-fold } \uparrow \text { cortex, cerebellum, } \\
\text { hippocampus } \\
\text { Expressed in MN + GFAP }{ }^{+v e} \\
\text { astroglia }\end{array}$ & No $\Delta$ (prolonged 4.2 days) & - & No $\triangle$ & [146] \\
\hline & $\mathrm{SOD} 1^{\mathrm{G} 93 \mathrm{~A}}$ & - & No $\Delta$ (died 6 days sooner) & $24 \% \uparrow$ & No $\triangle$ & [147] \\
\hline HSJ1a Tg & $\mathrm{SOD} 1^{\mathrm{G} 93 \mathrm{~A}}$ & 7-fold $\uparrow$ & No $\triangle$ & $61 \% \uparrow$ & No $\triangle$ & [148] \\
\hline \multirow[t]{3}{*}{$\mathrm{Hsp70} \mathrm{Tg}$} & $\mathrm{SOD} 1^{\mathrm{G} 93 \mathrm{~A}}$ & 10-fold $\uparrow$ & No $\Delta$ (prolonged 1.4 days) & - & - & [145] \\
\hline & $\mathrm{SOD} 1^{\mathrm{G} 85 \mathrm{R}}$ & 10-fold $\uparrow$ spinal cord & No $\triangle$ & - & - & \\
\hline & $\mathrm{SOD} 1^{\mathrm{G} 37 \mathrm{R}}$ & 10-fold $\uparrow$ & No $\triangle$ & - & - & \\
\hline $\begin{array}{l}\text { Hsp70 administered } \\
\text { exogenously }\end{array}$ & $\mathrm{SOD} 1^{\mathrm{G} 93 \mathrm{~A}}$ & $\begin{array}{l}\text { rhHsp70 injected } 3 \times \text { weekly } \\
(20 \mu g)-\text { detected in muscle } \\
\text { not CNS }\end{array}$ & 9 days & $12.5 \% \uparrow$ & - & [149] \\
\hline HSF1 Tg & $\mathrm{SOD} 1^{\mathrm{H} 46 \mathrm{R} / \mathrm{H} 48 \mathrm{Q}}$ & 3-fold $\uparrow$ & No $\triangle$ & - & $34 \% \downarrow$ & [151] \\
\hline SIRT1 Tg & $\mathrm{SOD} 1^{\mathrm{G} 93 \mathrm{~A}}$ & 3-fold $\uparrow$ & 15 days & - & $40 \% \downarrow$ & [150] \\
\hline \multirow[t]{2}{*}{ Withaferin A } & $\mathrm{SOD} 1^{\mathrm{G} 93 \mathrm{~A}}$ & $\begin{array}{l}\text { 2.6-fold } \uparrow \text { Hsp } 25 \\
\text { 2.2-fold } \uparrow \text { Hsp70 } \\
\text { Phosphorylated HSF1 }\end{array}$ & 8 days & $30 \% \uparrow$ & $39 \% \downarrow$ & [152] \\
\hline & $\mathrm{SOD} 1^{\mathrm{G} 37 \mathrm{R}}$ & - & 18 days & - & - & \\
\hline Celastrol & $\mathrm{SOD} 1^{\mathrm{G} 93 \mathrm{~A}}$ & - & 16 days & $30 \% \uparrow$ & - & [153] \\
\hline Arimoclomol & SOD1 $1^{\text {G93A }}$ & $\begin{array}{l}\text { 3-fold } \uparrow \text { Hsp70 } \\
\text { 2.5-fold } \uparrow \text { Hsp90 } \\
\text { Phosphorylated HSF1 }\end{array}$ & 28 days & $74 \% \uparrow$ & - & [154] \\
\hline NXD30001 & $\mathrm{SOD} 1^{\mathrm{G} 93 \mathrm{~A}}$ & $\begin{array}{l}\text { No } \uparrow \text { in Hsps in the CNS } \\
\uparrow \text { Hsp70 in skeletal muscle }\end{array}$ & - & - & - & [170] \\
\hline
\end{tabular}

Double transgenic (Tg) mice were bred for the over-expression of an Hsp and a SOD1 mutant associated with ALS. Alternatively, mice that over-express mSOD1 were treated with a therapeutic compound for the activation of the HSR. The fold increase in Hsp levels (and, if reported, the tissue-type in which this occurs), number of extended days of life, percent increase $(\uparrow)$ or decrease $(\downarrow)$ in spinal cord motor neurons, and percent $\uparrow$ or $\downarrow$ in the levels of inclusions is reported for each study

capable of reducing insoluble $\mathrm{Htt}$ and extending survival by 17, 21 and 32 days, respectively [156-159]. These findings illustrate how specific sets of Hsps may be more efficacious against aggregating proteins associated with HD. Furthermore, molecules that activate HSF1 and upregulate the HSR (and therefore increase expression of a broad range of stress-related proteins) appear to be more capable of reducing protein aggregate load, preventing neurodegeneration and increasing lifespan of mouse models of NDs compared to up-regulation of individual chaperones.

Investigations into the therapeutic benefit of pharmacological activation of the HSR in the context of NDs are currently in progress. There are two classes of therapeutics under investigation, each target different aspects of the HSR pathway. One class of therapeutics activate HSF1 and/or up-regulate downstream products of the HSR. These include celastrol, arimoclomol, withaferin A, acetyl, L-carnitine and pyrrolidine dithiocarbamate [160-164]. Thus far, arimoclomol is the most promising HSRmediating therapeutic. Administration of arimoclomol to mouse models of ALS (10 mg/kg/day), spinal and bulbar muscular atrophy $(120 \mathrm{mg} / \mathrm{kg} /$ day $)$ and inclusion body myositis $(120 \mathrm{mg} / \mathrm{kg} /$ day $)$ ameliorated neuropathologies associated with each disease, and arimoclomol successfully passed phase I human clinical trials in 2008 [154, 165167]. However, there is currently limited information regarding that status of phase II/III trials of arimoclomol in ALS patients.

Another class of therapeutics targets the HSF1 inhibitory complex composed of Hsp90, co-chaperone p23 and immunophilin FK506-binding protein 5. Since, Hsp90 activities are ATP-dependent, this complex can be targeted by small molecules that compete with ATP for binding to Hsp90. Radicicol, NVP-HSP990, geldanamycin and geldanamycin-derived 17-allylaminogeldanamycin are Hsp90 inhibitors that act in this way and have been investigated for the treatment of NDs [72, 75, 168, 169]. In HD mouse models, NVP-HSP990-induced induction of the HSR in CNS tissues but this effect declined with increasing age of mice and despite a $20 \%$ decline in inclusion load, no extension of life was observed [75]. Furthermore, 
Table 4 The effect of the over-expression of Hsps and up-regulation of the HSR on the molecular pathologies developed in rodent models of HD

\begin{tabular}{|c|c|c|c|c|c|c|}
\hline $\begin{array}{l}\text { Transgenic model/Therapeutic } \\
\text { compound }\end{array}$ & $\begin{array}{l}\mathrm{HD} \\
\text { model }\end{array}$ & Increase in Hsp in Tg mouse & $\begin{array}{l}\text { Extended } \\
\text { lifespan }\end{array}$ & $\begin{array}{l}\% \uparrow / \downarrow \text { in } \\
\text { surviving neurons }\end{array}$ & $\begin{array}{l}\% \uparrow / \downarrow \text { in levels of } \\
\text { inclusions }\end{array}$ & References \\
\hline aB-c Tg (astroglia only) & $\mathrm{BACHD}$ & - & - & $12.5 \% \uparrow$ & $50 \% \downarrow$ & [92] \\
\hline $\mathrm{Hsp} 27 \mathrm{Tg}$ & $\mathrm{R} 6 / 2$ & 12 -fold $\uparrow$ & - & - & No $\triangle$ & [180] \\
\hline \multirow[t]{2}{*}{ Hsp70 Tg } & $\mathrm{R} 6 / 2$ & Rat Hsp70 & - & - & No $\triangle$ & {$[72]$} \\
\hline & & 5-15-fold $\uparrow$ human Hsp70 & No $\triangle$ & No $\triangle$ & No $\triangle$ & [181] \\
\hline $\begin{array}{l}\text { rAAV-QBP1-Hsc70 } \\
\text { binding motif }\end{array}$ & $\mathrm{R} 6 / 2$ & Injected into the striatum & 32 days & - & $90.8 \% \downarrow$ & {$[158]$} \\
\hline rAAV-DNAJB1 & $\mathrm{R} 6 / 2$ & Injected into the striatum & 17 days & - & $39.2 \% \downarrow$ & [159] \\
\hline DNAJB6 Tg & $\mathrm{R} 6 / 2$ & $\begin{array}{l}\text { Brain-specific up-regulation } \\
\text { (nestin promoter) }\end{array}$ & 21 days & - & $33 \% \downarrow$ & {$[157]$} \\
\hline HSJa Tg & $\mathrm{R} 6 / 2$ & Brain specific up-regulation & No $\triangle$ & No $\triangle$ & $35 \% \downarrow$ & [182] \\
\hline Hsp104 & $\begin{array}{l}\text { N171-82Q } \\
\text { HD }\end{array}$ & $\begin{array}{l}\text { "Strongly" expressed in the } \\
\text { brain, heart kidneys, testis }\end{array}$ & - & - & No $\triangle$ & [183] \\
\hline $\mathrm{HSF}^{\text {Active }} \mathrm{Tg}$ & $\mathrm{R} 6 / 2$ & $\begin{array}{l}\text { Expressed in skeletal muscle, } \\
\text { heart and testes }\end{array}$ & 15 days & No $\triangle$ & $79 \% \downarrow$ & {$[155]$} \\
\hline $\begin{array}{l}\text { NVP-HSP990 } \\
\text { treatment }\end{array}$ & $\mathrm{R} 6 / 2$ & $\begin{array}{l}2.7 \text {-fold } \uparrow \text { Hsp70 } \\
3.8 \text {-fold } \uparrow \text { Hsp25 } \\
1.6 \text {-fold } \uparrow \text { Hsp40 }\end{array}$ & No $\triangle$ & - & $20 \% \downarrow$ & [75] \\
\hline HSF1 KO & $\mathrm{R} 6 / 2$ & - & $\begin{array}{l}105 \text { day decrease } \\
\text { in lifespan }\end{array}$ & - & $15 \% \uparrow$ & [184] \\
\hline HSF2 KO & $\mathrm{R} 6 / 2$ & - & $\begin{array}{l}91 \text { day decrease } \\
\text { in lifespan }\end{array}$ & - & $20 \% \uparrow$ & [185] \\
\hline
\end{tabular}

Double transgenic (Tg) mice were bred for the over-expression of an Hsp and polyQ-expanded Htt associated with HD. Alternatively, HSF1 and HSF2 genes were knocked-out (KO) of HD mouse models. Lentiviral vectors for the expression of QBP1-Hsc70 binding motif and DNAJB1 were injected directly into the striatum of R6/2 mice. In one case, mice that over-express polyQ-expanded Htt were treated with NVP-HSP990, a therapeutic compound for the activation of the HSR. The fold increase in Hsp levels (and, if reported, the tissue-type in which this occurs), number of extended days of life, percent increase ( $\uparrow$ ) or decrease ( $\downarrow$ ) in spinal cord motor neurons, and percent $\uparrow$ or $\downarrow$ in the levels of inclusions is reported for each study

in ALS mouse models, NXD30001 failed to induce the HSR in the CNS, despite the brain permeability of this molecule [170]. In vivo assessments investigating the efficacy of these compounds in the induction of the HSR has led to the conclusion that Hsp90 inhibitors are cytotoxic and not promising candidates to pursue for clinical trials.

A novel molecule identified in a yeast-based highthroughput screen, HSF1A, activates HSF1 by interacting with components of the inhibitory TRiC/CCT complex [171]. Treatment of cells with HSF1A results in HSF1 nuclear accumulation, trimerization, and enhanced binding to DNA [171]. Treatment of PC12 cells expressing polyQ-expanded Htt with HSF1A resulted in the reduction of inclusion bodies formed and protected cells against toxicity [171]. Furthermore, recent evidence shows that treatment of Neuro-2a cells transfected to express TDP-43- $\Delta$ NLS-K145Q with HSF1A results in $\mathrm{a} \sim 60 \%$ reduction in the number of aggregates formed compared to the vehicle control [172]. This indicates that the activation of endogenous HSF1 by HSF1A is sufficient to suppress mutant TDP-43 expression in this cell-based model [172]; however, it remains to be established whether HSF1A provides protection in vivo, in transgenic mouse models of NDs.
The therapeutic strategy of activating HSF1 in the CNS in the context of NDs is a promising one. Over 3 decades of research has provided strong in vitro evidence that activating HSF1 can reduce protein inclusion formation and ameliorate other molecular pathologies associated with a range of NDs [155, 172, 173]. However, progress towards the development of therapeutic compounds, that activate the HSR in affected tissues and cell-types in NDs has been slow. This is the likely due to the complexity of HSR induction in vivo, for example, in CNS tissues, Hsps may be provided to neurons in a noncell autonomous manner that cannot be assessed in initial drug screens that are performed in vitro. Drug screens need to move beyond simple cell-based models and begin to incorporate more advanced tissue culture approaches to consider the responses from the multiple cell types present in tissues.

\section{Conclusions}

This review has highlighted the complexity of the HSF1mediated HSR and demonstrated that the generic model for its induction and attenuation does not take into account additional layers of regulation that are stress- and cell-type specific. This review highlights that regulation 
in the induction of the HSR differs not only between cell types (e.g. neurons and astroglia) but also between neuronal sub-types in different regions of the brain (e.g. striatal neurons and motor neurons). It is these regulatory aspects of the HSR that are of particular interest with regards to the cells that comprise the CNS, where protein inclusion formation associated with NDs occurs. We propose that the appearance of protein inclusions in discrete neuronal populations in NDs may result from low (or no) basal levels of Hsps and/or a high threshold of HSR induction in these cells. Indeed, two recent findings in an $\alpha$-synucleinopathy and HD suggest a possible generic underlying pathology in NDs, whereby HSF1 is targeted for degradation by the proteasome through elevated expression or activity of ubiquitinases [25, 74]. Furthermore, evidence from a range of models of NDs indicates that the species formed during protein misfolding and aggregation do not cause sufficient cellular stress to induce an HSR in affected neurons and astroglia. This suggests that cell-autonomous and noncell-autonomous mechanisms that maintain protein homeostasis are insufficient to prevent protein aggregation associated with NDs in the CNS and highlights that the HSR is a promising pathway to target in the development of novel therapeutics for these diseases.

Future research should investigate basal and stressinducible HSR proteins in neurons and astroglia, preferably using quantitative, high throughput and single-cell analysis techniques, which circumvent contamination by other cell types. This is particularly important due to the growing body of evidence that implicates neuronalastroglial interactions in the progression of ALS and HD into late- and end-stage disease (as is also the case for other NDs). In addition, it is important to investigate the mechanisms by which astroglia can be maintained in a neurotrophic (rather than neurotoxic) phenotype in NDs. In compiling this review, it highlighted to us that there is a scarcity of research that has investigated the HSR in astroglia in the context of ALS or HD (and indeed most NDs). Furthermore, the ability of astroglia to provide non-cell-autonomous support to neurons by trafficking Hsps and other neurotrophic factors in exosomes is currently understudied in physiologically relevant models. Future research in this field should investigate the HSR in NDs by adopting a more holistic approach and focus on defining the cell-autonomous and non-cell-autonomous HSR within different cellstypes of the CNS.

\footnotetext{
Abbreviations

ALS: Amyotrophic lateral sclerosis; ANG: Angiogenin; C9ORF72: Chromosome 9 open reading frame 72; CCNF: Cyclin F; CD11b: Cluster of differentiation molecule 11B; ChIP: Chromatin immunoprecipitation; CNS: Central nervous system; DBD: DNA binding domain; DNA: Deoxyribonucleic acid; fALS: Familial amyotrophic lateral sclerosis; FUS: Fused in sarcoma; GFAP: Glial fibrillary acidic protein; GLAST: Glutamate aspartate transporter; GLT-
}

1: Glutamate transporter; HD: Huntington's disease; HSE: Heat shock element; HSF1: Heat shock transcription factor 1; Hsps: Heat shock proteins; HSR: Heat shock response; Htt: Huntingtin; IPOD: Perivacuolar inclusion bodies; JUNQ: Juxtanuclear compartments; KO: Knock-out; LZD: Leucine zipper domain; mRNA: Messenger ribonucleic acid; mSOD1: Mutant superoxide dismutase 1; NDs: Neurodegenerative diseases; NMDA: N-methyl-D-aspartate; OTPN: Optineurin; PCR: Polymerase chain reaction; PolyQ: Polyglutamine; QBP: Polyglutamine binding peptide; qPCR: Quantitative polymerase chain reaction; RD: Regulatory domain; RNA: Ribonucleic acid; sHsps: Small heat shock proteins; SOD1: Superoxide dismutase 1; SUMO: Small ubiquitin like modifier; TAD: Transactivation domain; TDP-43: TAR DNA binding protein; Tg: Transgenic; TRiC/CCT: T-complex protein-1 ring complex/chaperonin containing TCP1; UBQLN2: Ubiquilin 2; WT: Wild-type; aB-c: AlphaB-crystallin

\section{Acknowledgements}

We thank the Illawarra Health and Medical Research Institute for their technical and administrative support.

\section{Funding}

RSG is supported by an Australian Government Research Training Program Scholarship. JJY is supported by an NHMRC Career Development Fellowship (1084144).

\section{Availability of data and materials}

Not applicable.

\section{Authors' contributions}

RSG, LO, JJY and HE conceived of the review. RSG wrote the initial review and constructed the figures. RSG, LO, JJY and HE contributed to the editing of the manuscript. All authors read and approved the final manuscript.

\section{Authors' information}

Not applicable.

Ethics approval and consent to participate Not applicable.

\section{Competing interests}

The authors declare that they have no competing interests.

\section{Publisher's Note}

Springer Nature remains neutral with regard to jurisdictional claims in published maps and institutional affiliations.

Received: 25 June 2017 Accepted: 1 September 2017

Published online: 18 September 2017

\section{References}

1. Chiti F, Dobson CM. Protein misfolding, functional amyloid, and human disease. Annu Rev Biochem. 2006;75:333-66.

2. Verbeke P, Fonager J, Clark BF, Rattan SI. Heat shock and aging: mechanisms and implications. Cell Biol Int. 2001;25:845-57.

3. Douglas PM, Dillin A. Protein homeostasis and aging in neurodegeneration. J Cell Biol. 2010;190:719-29.

4. Brehme M, Voisine C, Rolland T, Wachi S, Soper JH, Zhu Y, Orton K, Villella A, Garza D, Vidal M, et al. A chaperome subnetwork safeguards proteostasis in aging and neurodegenerative disease. Cell Rep. 2014;9:1135-50.

5. Hartl FU, Bracher A, Hayer-Hartl M. Molecular chaperones in protein folding and proteostasis. Nature. 2011;475:324-32.

6. Balchin D, Hayer-Hartl M, Hartl FU. In vivo aspects of protein folding and quality control. Science. 2016;353.

7. Kampinga $\mathrm{HH}$, Bergink $\mathrm{S}$. Heat shock proteins as potential targets for protective strategies in neurodegeneration. Lancet Neurol. 2016;15:748-59.

8. Wyatt AR, Yerbury JJ, Ecroyd H, Wilson MR. Extracellular chaperones and proteostasis. Annu Rev Biochem. 2013;82:295-322.

9. Leak RK. Heat shock proteins in neurodegenerative disorders and aging. J Cell Commun Signal. 2014;8:293-310.

10. Treweek TM, Meehan S, Ecroyd H, Carver JA. Small heat-shock proteins: important players in regulating cellular proteostasis. Cell Mol Life Sci. 2015; 72:429-51. 
11. Yerbury JJ, Gower D, Vanags L, Roberts K, Lee JA, Ecroyd H. The small heat shock proteins alphaB-crystallin and Hsp27 suppress SOD1 aggregation in vitro. Cell Stress Chaperon. 2013;18:251-7.

12. Robertson AL, Headey SJ, Saunders HM, Ecroyd H, Scanlon MJ, Carver JA, Bottomley SP. Small heat-shock proteins interact with a flanking domain to suppress polyglutamine aggregation. Proc Natl Acad Sci U S A. 2010;107: 10424-9.

13. Evans CG, Wisen S, Gestwicki JE. Heat shock proteins 70 and 90 inhibit early stages of amyloid beta-(1-42) aggregation in vitro. J Biol Chem. 2006;281: 33182-91.

14. Wilhelmus MM, Boelens WC, Otte-Holler I, Kamps B, de Waal RM, Verbeek MM. Small heat shock proteins inhibit amyloid-beta protein aggregation and cerebrovascular amyloid-beta protein toxicity. Brain Res. 2006;1089:67-78.

15. Muchowski PJ, Schaffar G, Sittler A, Wanker EE, Hayer-Hartl MK, Hartl FU. Hsp70 and Hsp40 chaperones can inhibit self-assembly of polyglutamine proteins into amyloid-like fibrils. Proc Natl Acad Sci U S A. 2000;97:7841-6.

16. Howarth JL, Glover CPJ, Uney JB. HSP70 Interacting protein prevents the accumulation of inclusions in polyglutamine disease. J Neurochem. 2009; 108:945-51.

17. Watanabe M, Dykes-Hoberg M, Cizewski Culotta V, Price DL, Wong PC, Rothstein JD. Histological evidence of protein aggregation in mutant SOD1 transgenic mice and in amyotrophic lateral sclerosis neural tissues. Neurobiol Dis. 2001;8:933-41.

18. Wilhelmus MMM, Otte-Höller I, Wesseling P, De Waal RMW, Boelens WC, Verbeek MM. Specific association of small heat shock proteins with the pathological hallmarks of Alzheimer's disease brains. Neuropath Appl Neuro. 2006:32:119-30.

19. Jana NR, Tanaka M, Wang G-H, Nukina N. Polyglutamine length-dependent interaction of Hsp40 and Hsp70 family chaperones with truncated Nterminal huntingtin: their role in suppression of aggregation and cellular toxicity. Hum Mol Genet. 2000;9:2009-18.

20. Åkerfelt M, Morimoto Rl, Sistonen L. Heat shock factors: integrators of cell stress, development and lifespan. Nat Rev Mol Cell Biol. 2010;11:545-55.

21. Vihervaara A, Sistonen L. HSF1 At a glance. J Cell Sci. 2014;127:261-6.

22. Anckar J, Sistonen L. Regulation of HSF1 function in the heat stress response: implications in aging and disease. Annu Rev Biochem. 2011;80:1089-115.

23. Xu Y-M, Huang D-Y, Chiu J-F, Lau ATY. Post-translational modification of human heat shock factors and their functions: a recent update by proteomic approach. J Proteome Res. 2012;11:2625-34.

24. Westerheide SD, Anckar J, Stevens SM Jr, Sistonen L, Morimoto RI. Stressinducible regulation of heat shock factor 1 by the deacetylase SIRT1. Science. 2009;323:1063-6.

25. Kim E, Wang B, Sastry N, Masliah E, Nelson PT, Cai H, Liao F-F. NEDD4Mediated HSF1 degradation underlies a-synucleinopathy. Hum Mol Genet. 2016;25:211-22

26. Hietakangas V, Ahlskog JK, Jakobsson AM, Hellesuo M, Sahlberg NM, Holmberg Cl, Mikhailov A, Palvimo JJ, Pirkkala L, Sistonen L. Phosphorylation of serine 303 is a prerequisite for the stress-inducible SUMO modification of heat shock factor 1. Mol Cell Biol. 2003;23:2953-68.

27. Velichko A, Markova E, Petrova N, Razin S, Kantidze O. Mechanisms of heat shock response in mammals. Cell Mol Life Sci. 2013;70:4229-41.

28. Zheng X, Krakowiak J, Patel N, Beyzavi A, Ezike J, Khalil AS, Pincus D. Dynamic control of Hsf1 during heat shock by a chaperone switch and phosphorylation. elife. 2016;5:e18638.

29. Guettouche T, Boellmann F, Lane W, Voellmy R. Analysis of phosphorylation of human heat shock factor 1 in cells experiencing a stress. BMC Biochem. 2005;6:4.

30. Holmberg Cl, Hietakangas $\mathrm{V}$, Mikhailov A, Rantanen JO, Kallio M, Meinander A, Hellman J, Morrice N, MacKintosh C, Morimoto Rl, et al. Phosphorylation of serine 230 promotes inducible transcriptional activity of heat shock factor 1. EMBO J. 2001;20:3800-10.

31. Soncin F, Zhang X, Chu B, Wang X, Asea A, Stevenson M, Sacks D, Calderwood S. Transcriptional activity and DNA binding of heat shock factor-1 involve phosphorylation on threonine 142 by CK2. Biochem Biophys Res Commun. 2003;303:700-6.

32. Chafekar SM, Duennwald ML. Impaired heat shock response in cells expressing full-length polyglutamine-expanded huntingtin. PLoS One. 2012;7:e37929.

33. Mathur SK, Sistonen L, Brown IR, Murphy SP, Sarge KD, Morimoto RI. Deficient induction of human hsp70 heat shock gene transcription in Y79 retinoblastoma cells despite activation of heat shock factor 1. Proc Natl Acad Sci U S A. 1994;91:8695-9.
34. Raychaudhuri S, Loew C, Körner R, Pinkert S, Theis M, Hayer-Hartl M, Buchholz F, Hartl FU. Interplay of acetyltransferase EP300 and the proteasome system in regulating heat shock transcription factor 1. Cell. 2014;156:975-85.

35. Yang J, Oza J, Bridges K, Chen KY, Liu AY. Neural differentiation and the attenuated heat shock response. Brain Res. 2008;1203:39-50.

36. Neef DW, Jaeger AM, Thiele DJ. Heat shock transcription factor 1 as a therapeutic target in neurodegenerative diseases. Nat Rev Drug Discov. 2011;10:930-44.

37. Sandqvist A, Björk JK, Åkerfelt M, Chitikova Z, Grichine A, Vourc'h C, Jolly C, Salminen TA, Nymalm $Y$, Sistonen L. Heterotrimerization of heat-shock factors 1 and 2 provides a transcriptional switch in response to distinct stimuli. Mol Biol Cell. 2009;20:1340-7.

38. Rabindran SK, Haroun RI, Clos J, Wisniewski J, Wu C. Regulation of heat shock factor trimer formation: role of a conserved leucine zipper. Science. 1993;259:230-4.

39. Pelham HR. A regulatory upstream promoter element in the Drosophila Hsp 70 heat-shock gene. Cell. 1982:30:517-28.

40. Sorger PK, Pelham HR. Yeast heat shock factor is an essential DNA-binding protein that exhibits temperature-dependent phosphorylation. Cell. 1988;54: 855-64.

41. Amin J, Ananthan J, Voellmy R. Key features of heat shock regulatory elements. Mol Cell Biol. 1988;8:3761-9.

42. Xiao H, Lis J. Germline transformation used to define key features of heatshock response elements. Science. 1988;239:1139-42.

43. Trinklein N, Chen W, Kingston R, Myers R. Transcriptional regulation and binding of heat shock factor 1 and heat shock factor 2 to 32 human heat shock genes during thermal stress and differentiation. Cell Stress Chaperon. 2004;9:21-8.

44. Trinklein N, Murray J, Hartman S, Botstein D, Myers R. The role of heat shock transcription factor 1 in the genome-wide regulation of the mammalian heat shock response. Mol Biol Cell. 2004;15:1254-61.

45. Bharadwaj S, Ali A, Ovsenek N. Multiple components of the HSP90 chaperone complex function in regulation of heat shock factor 1 in vivo. Mol Cell Biol. 1999;19:8033-41.

46. Guo Y, Guettouche T, Fenna M, Boellmann F, Pratt WB, Toft DO, Smith DF, Voellmy R. Evidence for a mechanism of repression of heat shock factor 1 transcriptional activity by a multichaperone complex. J Biol Chem. 2001;276: 45791-9.

47. Neef DW, Jaeger A, Gomez-Pastor R, Willmund F, Frydman J, Thiele DJ. A direct regulatory interaction between chaperonin $\mathrm{TRiC}$ and stress responsive transcription factor HSF1. Cell Rep. 2014;9:955-66.

48. Shi Y, Mosser DD, Morimoto RI. Molecular chaperones as HSF1-specific transcriptional repressors. Genes Dev. 1998;12:654-66.

49. Gómez AV, Galleguillos D, Maass JC, Battaglioli E, Kukuljan M, Andrés ME. COREST represses the heat shock response mediated by HSF1. Mol Cell. 2008;31:222-31.

50. Blake MJ, Gershon D, Fargnoli J, Holbrook NJ. Discordant expression of heat shock protein mRNAs in tissues of heat-stressed rats. J Biol Chem. 1990;265: 15275-9.

51. Nishimura RN, Dwyer BE, Clegg K, Cole R, de Vellis J. Comparison of the heat shock response in cultured cortical neurons and astrocytes. Mol Brain Res. 1991;9:39-45.

52. Sala AJ, Bott LC, Morimoto RI. Shaping proteostasis at the cellular, tissue, and organismal level. J Cell Biol. 2017;216:1231-41.

53. Batulan Z, Shinder GA, Minotti S, He BP, Doroudchi MM, Nalbantoglu J, Strong MJ, Durham HD. High threshold for induction of the stress response in motor neurons is associated with failure to activate HSF1. J Neurosci. 2003;23:5789-98.

54. Oza J, Yang J, Chen K, Liu AC. Changes in the regulation of heat shock gene expression in neuronal cell differentiation. Cell Stress Chaperon. 2008;13:73-84.

55. Pavlik A, Aneja IS. Cerebral neurons and glial cell types inducing heat shock protein Hsp70 following heat stress in the rat. Prog Brain Res. 2007;162:417-31.

56. Nishimura RN, Dwyer BE. Evidence for different mechanisms of induction of HSP70i: a comparison of cultured rat cortical neurons with astrocytes. Brain Res Mol Brain Res. 1996;36:227-39.

57. Manzerra P, Rush SJ, Brown IR. Tissue-specific differences in heat shock protein $\mathrm{Hsc70}$ and $\mathrm{Hsp} 70$ in the control and hyperthermic rabbit. J Cell Physiol. 1997;170:130-7.

58. Manzerra P, Brown IR. Expression of heat shock genes (Hsp70) in the rabbit spinal cord: localization of constitutive and hyperthermia-inducible mRNA species. J Neurosci Res. 1992;31:606-15. 
59. Krueger AM, Armstrong JN, Plumier J, Robertson HA, Currie RW. Cell specific expression of Hsp70 in neurons and glia of the rat hippocampus after hyperthermia and kainic acid-induced seizure activity. Brain Res Mol Brain Res. 1999;71:265-78.

60. Vonsattel JP, DiFiglia M. Huntington disease. J Neuropathol Exp Neurol. 1998:57:369-84

61. Han I, You Y, Kordower JH, Brady ST, Morfini GA. Differential vulnerability of neurons in Huntington's disease: the role of cell type-specific features. J Neurochem. 2010;113:1073-91.

62. MacDonald ME, Ambrose CM, Duyao MP, Myers RH, Lin C, Srinidhi L, Barnes G, Taylor SA, James M, Groot N, et al. A novel gene containing a trinucleotide repeat that is expanded and unstable on Huntington's disease chromosomes. Cell. 1993;72:971-83.

63. Zoghbi HY, Orr HT. Glutamine repeats and neurodegeneration. Annu Rev Neurosci. 2000;23:217-47.

64. Kaganovich D, Kopito R, Frydman J. Misfolded proteins partition between two distinct quality control compartments. Nature. 2008;454:1088-95.

65. Kayatekin C, Matlack KE, Hesse WR, Guan Y, Chakrabortee S, Russ J, Wanker $\mathrm{EE}$, Shah JV, Lindquist S. Prion-like proteins sequester and suppress the toxicity of huntingtin exon 1. Proc Natl Acad Sci U S A. 2014;111:12085-90.

66. Polling S, Mok YF, Ramdzan YM, Turner BJ, Yerbury JJ, Hill AF, Hatters DM. Misfolded polyglutamine, polyalanine, and superoxide dismutase 1 aggregate via distinct pathways in the cell. J Biol Chem. 2014;289: 6669-80.

67. Ramdzan YM, Trubetskov MM, Ormsby AR, Newcombe EA, Sui X, Tobin MJ, Bongiovanni MN, Gras SL, Dewson G, Miller JML, et al. Huntingtin inclusions trigger cellular quiescence, deactivate apoptosis, and lead to delayed necrosis. Cell Rep. 2017;19:919-27.

68. Matsumoto G, Kim S, Morimoto RI. Huntingtin and mutant SOD1 form aggregate structures with distinct molecular properties in human cells. J Biol Chem. 2006;281:4477-85.

69. Farrawell NE, Lambert-Smith IA, Warraich ST, Blair IP, Saunders DN, Hatters DM, Yerbury JJ. Distinct partitioning of ALS associated TDP-43, FUS and SOD1 mutants into cellular inclusions. Sci Rep. 2015:5:13416.

70. Bersuker K, Hipp MS, Calamini B, Morimoto RI, Kopito RR. Heat shock response activation exacerbates inclusion body formation in a cellular model of Huntington disease. J Biol Chem. 2013;288:23633-8.

71. Tagawa K, Marubuchi S, Qi ML, Enokido Y, Tamura T, Inagaki R, Murata M, Kanazawa I, Wanker EE, Okazawa $H$. The induction levels of heat shock protein 70 differentiate the vulnerabilities to mutant huntingtin among neuronal subtypes. J Neurosci. 2007;27:868-80.

72. Hay DG, Sathasivam K, Tobaben S, Stahl B, Marber M, Mestril R, Mahal A, Smith DL, Woodman B, Bates GP. Progressive decrease in chaperone protein levels in a mouse model of Huntington's disease and induction of stress proteins as a therapeutic approach. Hum Mol Genet. 2004;13:1389-405.

73. Riva L, Koeva M, Yildirim F, Pirhaji L, Dinesh D, Mazor T, Duennwald ML, Fraenkel E. Poly-glutamine expanded huntingtin dramatically alters the genome wide binding of HSF1. J Huntingtons Dis. 2012;1:33-45.

74. Gomez-Pastor R, Burchfiel ET, Neef DW, Jaeger AM, Cabiscol E, McKinstry SU, Doss A, Aballay A, Lo DC, Akimov SS, et al. Abnormal degradation of the neuronal stress-protective transcription factor HSF1 in Huntington's disease. Nat Commun. 2017:8:14405.

75. Labbadia J, Cunliffe H, Weiss A, Katsyuba E, Sathasivam K, Seredenina T, Woodman B, Moussaoui S, Frentzel S, Luthi-Carter R, et al. Altered chromatin architecture underlies progressive impairment of the heat shock response in mouse models of Huntington disease. J Clin Invest. 2011;121:3306-19.

76. Jackrel ME, Shorter J. Shock and awe: unleashing the heat shock response to treat Huntington's disease. J Clin Invest. 2011;121:2972-5.

77. Guertin MJ, Lis JT. Chromatin landscape dictates HSF binding to target DNA elements. PLoS Genet. 2010;6:e1001114.

78. Zuccato C, Belyaev N, Conforti P, Ooi L, Tartari M, Papadimou E, MacDonald M, Fossale E, Zeitlin S, Buckley N, Cattaneo E. Widespread disruption of repressor element-1 silencing transcription factor/neuron-restrictive silencer factor occupancy at its target genes in Huntington's disease. J Neurosci. 2007;27:6972-83.

79. Wang J, Martin E, Gonzales V, Borchelt DR, Lee MK. Differential regulation of small heat shock proteins in transgenic mouse models of neurodegenerative diseases. Neurobiol Aging. 2008;29:586-97.

80. Liu X, Miller BR, Rebec GV, Clemmer DE. Protein expression in the striatum and cortex regions of the brain for a mouse model of Huntington's disease. J Proteome Res. 2007;6:3134-42.
81. Sharma K, Schmitt S, Bergner CG, Tyanova S, Kannaiyan N, Manrique-Hoyos N, Kongi K, Cantuti L, Hanisch U-K, Philips M-A, et al. Cell type- and brain region-resolved mouse brain proteome. Nat Neurosci. 2015;18:1819-31.

82. Gu X, Andre VM, Cepeda C, Li SH, Li XJ, Levine MS, Yang XW. Pathological cell-cell interactions are necessary for striatal pathogenesis in a conditional mouse model of Huntington's disease. Mol Neurodegener. 2007;2:8.

83. Gu X, Li C, Wei W, Lo V, Gong S, Li SH, Iwasato T, Itohara S, Li XJ, Mody I, et al. Pathological cell-cell interactions elicited by a neuropathogenic form of mutant Huntingtin contribute to cortical pathogenesis in HD mice. Neuron. 2005;46:433-44.

84. Bradford J, Shin JY, Roberts M, Wang CE, Sheng G, Li S, Li XJ. Mutant huntingtin in glial cells exacerbates neurological symptoms of Huntington disease mice. J Biol Chem. 2010;285:10653-61.

85. Faideau M, Kim J, Cormier K, Gilmore R, Welch M, Auregan G, Dufour N, Guillermier M, Brouillet E, Hantraye P, et al. In vivo expression of polyglutamine-expanded huntingtin by mouse striatal astrocytes impairs glutamate transport: a correlation with Huntington's disease subjects. Hum Mol Genet. 2010;19:3053-67.

86. Liddelow SA, Guttenplan KA, Clarke LE, Bennett FC, Bohlen CJ, Schirmer L, Bennett ML, Münch AE, Chung W-S, Peterson TC, et al. Neurotoxic reactive astrocytes are induced by activated microglia. Nature. 2017;541:481-7.

87. Bradford J, Shin J-Y, Roberts M, Wang C-E, Li X-J, Li S. Expression of mutant huntingtin in mouse brain astrocytes causes age-dependent neurological symptoms. Proc Natl Acad Sci U S A. 2009;106:22480-5.

88. Shin JY, Fang ZH, Yu ZX, Wang CE, Li SH, Li XJ. Expression of mutant huntingtin in glial cells contributes to neuronal excitotoxicity. J Cell Biol. 2005:171:1001-12.

89. Ruiz C, Casarejos MJ, Gomez A, Solano R, de Yebenes JG, Mena MA. Protection by glia-conditioned medium in a cell model of Huntington disease. PLoS Curr. 2012;4:e4fbca54a2028b.

90. Carnemolla A, Lazell H, Moussaoui S, Bates GP. In vivo profiling reveals a competent heat shock response in adult neurons: implications for neurodegenerative disorders. PLoS One. 2015;10:e0131985.

91. Jansen AHP, van Hal M, Op den Kelder IC, Meier RT, de Ruiter AA, Schut MH, Smith DL, Grit C, Brouwer N, Kamphuis W, et al. Frequency of nuclear mutant huntingtin inclusion formation in neurons and glia is cell-typespecific. Glia. 2017;65:50-61.

92. Oliveira AO, Osmand A, Outeiro TF, Muchowski PJ, Finkbeiner S. AlphaBcrystallin overexpression in astrocytes modulates the phenotype of the BACHD mouse model of Huntington's disease. Hum Mol Genet. 2016;25:1677-89.

93. Williams KL, Topp S, Yang S, Smith B, Fifita JA, Warraich ST, Zhang KY, Farrawell N, Vance C, Hu X, et al. CCNF mutations in amyotrophic lateral sclerosis and frontotemporal dementia. Nat Commun. 2016;7:11253.

94. Chen S, Sayana P, Zhang X, Le W. Genetics of amyotrophic lateral sclerosis: an update. Mol Neurodegener. 2013;8:28.

95. Iguchi $Y$, Katsuno M, Ikenaka K, Ishigaki S, Sobue G. Amyotrophic lateral sclerosis: an update on recent genetic insights. J Neurol. 2013;260:2917-27.

96. Asea AAA, Brown IR. Heat shock proteins and the brain: implications for neurodegenerative diseases and neuroprotection. In: AAA A, Calderwood SK, editors. Heat shock proteins, vol. 3. New York: Springer; 2008.

97. Bruijn LI, Miller TM, Cleveland DW. Unraveling the mechanisms involved in motor neuron degeneration in ALS. Annu Rev Neurosci. 2004;27:723-49.

98. Rothstein JD. Current hypotheses for the underlying biology of amyotrophic lateral sclerosis. Ann Neurol. 2009;65:S3-9.

99. Boillée S, Vande Velde C, Cleveland Don W. ALS: a disease of motor neurons and their nonneuronal neighbours. Neuron. 2006;52:39-59.

100. Tashiro $Y$, Urushitani M, Inoue H, Koike M, Uchiyama Y, Komatsu M, Tanaka K, Yamazaki M, Abe M, Misawa H, et al. Motor neuron-specific disruption of proteasomes, but not autophagy, replicates amyotrophic lateral sclerosis. J Biol Chem. 2012;287:42984-94.

101. Cheroni C, Marino M, Tortarolo M, Veglianese $P$, De Biasi S, Fontana $E$, Zuccarello LV, Maynard CJ, Dantuma NP, Bendotti C. Functional alterations of the ubiquitin-proteasome system in motor neurons of a mouse model of familial amyotrophic lateral sclerosis. Hum Mol Genet. 2009;18:82-96.

102. Prell T, Lautenschlager J, Witte OW, Carri MT, Grosskreutz J. The unfolded protein response in models of human mutant G93A amyotrophic lateral sclerosis. Eur J Neurosci. 2012;35:652-60.

103. Nishitoh $H$, Kadowaki $H$, Nagai A, Maruyama T, Yokota T, Fukutomi $H_{\text {, }}$ Noguchi T, Matsuzawa A, Takeda K, Ichijo H. ALS-linked mutant SOD1 induces ER stress- and ASK1-dependent motor neuron death by targeting Derlin-1. Genes Dev. 2008;22:1451-64. 
104. Ferrucci M, Fulceri F, Toti L, Soldani P, Siciliano G, Paparelli A, Fornai F: Protein clearing pathways in ALS. Arch Ital Biol 2011, 149:121-149.

105. Taylor JP, Brown RH Jr, Cleveland DW. Decoding ALS: from genes to mechanism. Nature. 2016;539:197-206.

106. Brown IR, Rush SJ. Cellular localization of the heat shock transcription factors HSF1 and HSF2 in the rat brain during postnatal development and following hyperthermia. Brain Res. 1999;821:333-40.

107. Batulan Z, Taylor DM, Aarons RJ, Minotti S, Doroudchi MM, Nalbantoglu J, Durham HD. Induction of multiple heat shock proteins and neuroprotection in a primary culture model of familial amyotrophic lateral sclerosis. Neurobiol Dis. 2006;24:213-25.

108. Yamashita H, Kawamata J, Okawa K, Kanki R, Nakamizo T, Hatayama T, Yamanaka K, Takahashi R, Shimohama S. Heat-shock protein 105 interacts with and suppresses aggregation of mutant Cu/Zn superoxide dismutase: clues to a possible strategy for treating ALS. J Neurochem. 2007:102:1497-505.

109. Charette SJ, Lavoie JN, Lambert H, Landry J. Inhibition of Daxx-mediated apoptosis by heat shock protein 27. Mol Cell Biol. 2000;20:7602-12.

110. Raoul C, Henderson CE, Pettmann B. Programmed cell death of embryonic motoneurons triggered through the FAS death receptor. J Cell Biol. 1999; 147:1049-62.

111. Raoul C, Estevez AG, Nishimune H, Cleveland DW, de Lapeyriere O, Henderson CE, Haase G, Pettmann B. Motoneuron death triggered by a specific pathway downstream of Fas. Potentiation by ALS-linked SOD1 mutations. Neuron. 2002;35:1067-83.

112. Raoul C, Barthelemy C, Couzinet A, Hancock D, Pettmann B, Hueber AO. Expression of a dominant negative form of Daxx in vivo rescues motoneurons from Fas (CD95)-induced cell death. J Neurobiol. 2005;62:178-88.

113. Maatkamp A, Vlug A, Haasdijk E, Troost D, French PJ, Jaarsma D. Decrease of Hsp25 protein expression precedes degeneration of motoneurons in ALSSOD1 mice. Eur J Neurosci. 2004;20:14-28.

114. Strey CW, Spellman D, Stieber A, Gonatas JO, Wang X, Lambris JD, Gonatas NK. Dysregulation of stathmin, a microtubule-destabilizing protein, and up-regulation of Hsp25, Hsp27, and the antioxidant peroxiredoxin 6 in a mouse model of familial amyotrophic lateral sclerosis. Am J Pathol. 2004;165:1701-18.

115. Wang J, Xu G, Li H, Gonzales V, Fromholt D, Karch C, Copeland NG, Jenkins NA, Borchelt DR. Somatodendritic accumulation of misfolded SOD1-L126Z in motor neurons mediates degeneration: aB-crystallin modulates aggregation. Hum Mol Gen. 2005;14:2335-47.

116. Vleminckx V, Van Damme $P$, Goffin $K$, Delye $H$, Van Den Bosch L, Robberecht W. Upregulation of HSP27 in a transgenic model of ALS. J Neuropathol Exp Neurol. 2002;61:968-74.

117. Chen $\mathrm{H}-$ J, Mitchell JC, Novoselov S, Miller J, Nishimura AL, Scotter EL, Vance CA, Cheetham ME, Shaw CE. The heat shock response plays an important role in TDP-43 clearance: evidence for dysfunction in amyotrophic lateral sclerosis. Brain. 2016;139(Pt 5):1417-32.

118. Kakkar V, Meister-Broekema M, Minoia M, Carra S, Kampinga HH. Barcoding heat shock proteins to human diseases: looking beyond the heat shock response. Dis Model Mech. 2014;7:421-34.

119. Lee J, Hyeon SJ, Im H, Ryu H, Kim Y, Ryu H. Astrocytes and microglia as non-cell autonomous players in the pathogenesis of ALS. Exp Neurobiol. 2016;25:233-40.

120. Pramatarova A, Laganiere J, Roussel J, Brisebois K, Rouleau GA. Neuronspecific expression of mutant superoxide dismutase 1 in transgenic mice does not lead to motor impairment. J Neurosci. 2001:21:3369-74.

121. Wong PC, Pardo CA, Borchelt DR, Lee MK, Copeland NG, Jenkins NA, Sisodia SS, Cleveland DW, Price DL. An adverse property of a familial ALS-linked SOD1 mutation causes motor neuron disease characterized by vacuolar degeneration of mitochondria. Neuron. 1995;14:1105-16.

122. Boillée S, Yamanaka K, Lobsiger CS, Copeland NG, Jenkins NA, Kassiotis G, Kollias G, Cleveland DW. Onset and progression in inherited ALS determined by motor neurons and microglia. Science. 2006;312:1389-92.

123. Yamanaka K, Chun SJ, Boillee S, Fujimori-Tonou N, Yamashita H, Gutmann DH, Takahashi R, Misawa H, Cleveland DW. Astrocytes as determinants of disease progression in inherited ALS. Nat Neurosci. 2008;11:251-3.

124. Ilieva H, Polymenidou M, Cleveland DW. Non-cell autonomous toxicity in neurodegenerative disorders: ALS and beyond. J Cell Biol. 2009;187:761-72.

125. Ditsworth D, Maldonado M, McAlonis-Downes M, Sun S, Seelman A Drenner K, Arnold E, Ling S-C, Pizzo D, Ravits J, et al. Mutant TDP-43 within motor neurons drives disease onset but not progression in amyotrophic lateral sclerosis. Acta Neuropathol. 2017;133:907-22.
126. Tong J, Huang C, Bi F, Wu Q, Huang B, Liu X, Li F, Zhou H, Xia XG. Expression of ALS-linked TDP-43 mutant in astrocytes causes non-cellautonomous motor neuron death in rats. EMBO J. 2013;32:1917-26.

127. Huang $C$, Huang B, Bi F, Yan LH, Tong J, Huang J, Xia XG, Zhou H. Profiling the genes affected by pathogenic TDP-43 in astrocytes. J Neurochem. 2014; 129:932-9.

128. Nagai M, Re DB, Nagata T, Chalazonitis A, Jessell TM, Wichterle $H$, Przedborski S. Astrocytes expressing ALS-linked mutated SOD1 release factors selectively toxic to motor neurons. Nat Neurosci. 2007;10:615-22.

129. Bilsland LG, Nirmalananthan N, Yip J, Greensmith L, Duchen MR. Expression of mutant SOD1G93A in astrocytes induces functional deficits in motoneuron mitochondria. J Neurochem. 2008;107:1271-83.

130. Di Giorgio FP, Carrasco MA, Siao MC, Maniatis T, Eggan K. Non-cell autonomous effect of glia on motor neurons in an embryonic stem cellbased ALS model. Nat Neurosci. 2007:10:608-14.

131. Cassina P, Cassina A, Pehar M, Castellanos R, Gandelman M, de Leon A, Robinson KM, Mason RP, Beckman JS, Barbeito L, Radi R. Mitochondrial dysfunction in SOD1G93A-bearing astrocytes promotes motor neuron degeneration: prevention by mitochondrial-targeted antioxidants. J Neurosci. 2008;28:4115-22

132. Peteranderl R, Nelson HCM. Trimerization of the heat shock transcription factor by a triple-stranded alpha-helical coiled-coil. Biochemistry. 1992;31:12272-6.

133. Westwood JT, Wu C. Activation of Drosophila heat shock factor: conformational change associated with a monomer-to-trimer transition. Mol Cell Biol. 1993;13:3481-6.

134. Neudegger T, Verghese J, Hayer-Hartl M, Hartl FU, Bracher A. Structure of human heat-shock transcription factor 1 in complex with DNA. Nat Struct Mol Biol. 2016:23:140-6.

135. Frühbeis C, Fröhlich D, Kuo WP, Krämer-Albers E-M. Extracellular vesicles as mediators of neuron-glia communication. Front Cell Neurosci. 2013;7:182.

136. Taylor AR, Robinson MB, Gifondorwa DJ, Tytell M, Milligan CE. Regulation of heat shock protein 70 release in astrocytes: role of signaling kinases. Dev Neurobiol. 2007;67:1815-29.

137. Guzhova I, Kislyakova K, Moskaliova O, Fridlanskaya I, Tytell M, Cheetham M, Margulis B. In vitro studies show that $\mathrm{Hsp} 70$ can be released by glia and that exogenous Hsp70 can enhance neuronal stress tolerance. Brain Res. 2001;914:66-73.

138. Bucciantini M, Giannoni E, Chiti F, Baroni F, Formigli L, Zurdo J, Tadde N, Ramponi G, Dobson CM, Stefani M. Inherent toxicity of aggregates implies a common mechanism for protein misfolding diseases. Nature. 2002:416:507-11.

139. Kayed R, Head E, Thompson JL, McIntire TM, Milton SC, Cotman CW, Glabe CG. Common structure of soluble amyloid oligomers implies common mechanism of pathogenesis. Science. 2003;300:486-9.

140. Muchowski PJ, Wacker JL. Modulation of neurodegeneration by molecular chaperones. Nat Rev Neurosci. 2005;6:11-22.

141. Duncan EJ, Cheetham ME, Chapple JP, van der Spuy J. The role of Hsp70 and its Co-chaperones in protein misfolding, aggregation and disease. In: Blatch GL, Edkins AL, editors. The networking of chaperones by cochaperones. Volume 78: Springer International Publishing; 2015. p. 243-73. Subcellular Biochemistry.

142. Pratt WB, Gestwicki JE, Osawa Y, Lieberman AP. Targeting Hsp90/Hsp70based protein quality control for treatment of adult onset neurodegenerative diseases. Annu Rev Pharmacol. 2015;55:353-71.

143. Bose S, Cho J. Targeting chaperones, heat shock factor-1, and unfolded protein response: promising therapeutic approaches for neurodegenerative disorders. Ageing Res Rev. 2017;35:155-75.

144. Calderwood SK, Murshid A. Molecular chaperone accumulation in cancer and decrease in Alzheimer's disease: the potential roles of HSF1. Front Neurosci. 2017;11:192

145. Liu J, Shinobu LA, Ward CM, Young D, Cleveland DW. Elevation of the Hsp70 chaperone does not effect toxicity in mouse models of familial amyotrophic lateral sclerosis. J Neurochem. 2005;93:875-82.

146. Krishnan J, Vannuvel K, Andries M, Waelkens E, Robberecht W, Van Den Bosch L. Over-expression of Hsp27 does not influence disease in the mutant SOD1G93A mouse model of amyotrophic lateral sclerosis. J Neurochem. 2008;106:2170-83.

147. Sharp PS, Akbar MT, Bouri S, Senda A, Joshi K, Chen H-J, Latchman DS, Wells DJ, de Belleroche J. Protective effects of heat shock protein 27 in a model of ALS occur in the early stages of disease progression. Neurobiol Dis. 2008; 30:42-55 
148. Novoselov SS, Mustill WJ, Gray AL, Dick JR, Kanuga N, Kalmar B, Greensmith L, Cheetham ME. Molecular chaperone mediated late-stage Neuroprotection in the SOD1G93A mouse model of amyotrophic lateral sclerosis. PLoS One. 2013;8:e73944.

149. Gifondorwa DJ, Robinson MB, Hayes CD, Taylor AR, Prevette DM, Oppenheim RW, Caress J, Milligan CE. Exogenous delivery of heat shock protein 70 increases lifespan in a mouse model of amyotrophic lateral sclerosis. J Neurosci. 2007;27:13173-80.

150. Watanabe S, Ageta-Ishihara N, Nagatsu S, Takao K, Komine O, Endo F, Miyakawa T, Misawa H, Takahashi R, Kinoshita M, Yamanaka K. SIRT1 overexpression ameliorates a mouse model of SOD1-linked amyotrophic lateral sclerosis via HSF1/HSP70i chaperone system. Mol Brain. 2014;7:62.

151. Lin P-Y, Simon SM, Koh WK, Folorunso O, Umbaugh CS, Pierce A. Heat shock factor 1 over-expression protects against exposure of hydrophobic residues on mutant SOD1 and early mortality in a mouse model of amyotrophic lateral sclerosis. Mol Neurodegener. 2013;8:43.

152. Patel $P$, Julien JP, Kriz J. Early-stage treatment with withaferin a reduces levels of misfolded superoxide dismutase 1 and extends lifespan in a mouse model of amyotrophic lateral sclerosis. Neurotherapeutics. 2014;

153. Kiaei M, Kipiani K, Petri S, Chen J, Calingasan NY, Beal MF. Celastrol blocks neuronal cell death and extends life in transgenic mouse model of amyotrophic lateral sclerosis. Neurodegener Dis. 2005;2:246-54.

154. Kieran D, Kalmar B, Dick JR, Riddoch-Contreras J, Burnstock G, Greensmith L. Treatment with arimoclomol, a coinducer of heat shock proteins, delays disease progression in ALS mice. Nat Med. 2004;10:402-5.

155. Fujimoto M, Takaki E, Hayashi T, Kitaura Y, Tanaka Y, Inouye S, Nakai A. Active HSF1 significantly suppresses polyglutamine aggregate formation in cellular and mouse models. J Biol Chem. 2005;280:34908-16.

156. Gillis J, Schipper-Krom S, Juenemann K, Gruber A, Coolen S, van den Nieuwendijk R, van Veen H, Overkleeft H, Goedhart J, Kampinga HH, Reits EA. The DNAJB6 and DNAJB8 protein chaperones prevent intracellular aggregation of polyglutamine peptides. J Biol Chem. 2013;288:17225-37.

157. Kakkar V, Månsson C, de Mattos EP, Bergink S, van der Zwaag M, van Waarde Maria AWH, Kloosterhuis Niels J, Melki R, van Cruchten Remco TP, Al-Karadaghi $\mathrm{S}$, et al. The S/T-rich motif in the DNAJB6 chaperone delays polyglutamine aggregation and the onset of disease in a mouse model. Mol Cell. 2016;62:272-83.

158. Bauer PO, Goswami A, Wong HK, Okuno M, Kurosawa M, Yamada M, Miyazaki H, Matsumoto G, Kino Y, Nagai Y, Nukina N. Harnessing chaperone-mediated autophagy for the selective degradation of mutant huntingtin protein. Nat Biotech. 2010;28:256-63.

159. Popiel HA, Takeuchi T, Fujita H, Yamamoto K, Ito C, Yamane H, Muramatsu S-I, Toda T, Wada K, Nagai Y. Hsp40 Gene therapy exerts therapeutic effects on polyglutamine disease mice via a non-cell autonomous mechanism. PLoS One. 2012;7:e51069.

160. Sharma S, Mishra R, Walker B, Deshmukh S, Zampino M, Patel J, Anamalai M, Simpson D, Singh I, Kaushal S, Kaushal S. Celastrol, an oral heat shock activator, ameliorates multiple animal disease models of cell death. Cell Stress Chaperon. 2015;20:185-201

161. Kalmar B, Lu C-H, Greensmith L. The role of heat shock proteins in amyotrophic lateral sclerosis: the therapeutic potential of arimoclomol. Pharmacol Therapeut. 2014;141:40-54.

162. Khan S, Rammeloo AW, Heikkila JJ. Withaferin a induces proteasome hnhibition, endoplasmic reticulum stress, the heat shock response and acquisition of thermotolerance. PLoS One. 2012;7:e50547.

163. Abdul HM, Calabrese V, Calvani M, Butterfield DA. Acetyl-L-carnitine-induced up-regulation of heat shock proteins protects cortical neurons against amyloid-beta peptide 1-42-mediated oxidative stress and neurotoxicity: implications for Alzheimer's disease. J Neurosci Res. 2006;84:398-408.

164. DeMeester SL, Buchman TG, Qiu Y, Dunnigan K, Hotchkiss RS, Karl IE, Cobb JP. Pyrrolidine dithiocarbamate activates the heat shock response and thereby induces apoptosis in primed endothelial cells. Shock. 1998;10:1-6.

165. Kalmar B, Novoselov S, Gray A, Cheetham ME, Margulis B, Greensmith L. Late stage treatment with arimoclomol delays disease progression and prevents protein aggregation in the SOD1 mouse model of ALS. J Neurochem. 2008;107:339-50.

166. Malik B, Nirmalananthan N, Gray AL, La Spada AR, Hanna MG, Greensmith L. Co-induction of the heat shock response ameliorates disease progression in a mouse model of human spinal and bulbar muscular atrophy: implications for therapy. Brain. 2013;136:926-43.

167. Ahmed M, MacHado PM, Miller A, Spicer C, Herbelin L, He J, Noel J, Wang Y, McVey AL, Pasnoor M, et al. Targeting protein homeostasis in sporadic inclusion body myositis. Sci Transl Med. 2016;8(331):331ra41.
168. Ortega L, Calvillo M, Luna F, Pérez-Severiano F, Rubio-Osornio M, Guevara J, Limón ID. 17-AAG improves cognitive process and increases heat shock protein response in a model lesion with A $225-35$. Neuropeptides. 2014:48:221-32.

169. Sittler A, Lurz R, Lueder G, Priller J, Lehrach H, Hayer-Hartl MK, Hartl FU, Wanker EE. Geldanamycin activates a heat shock response and inhibits huntingtin aggregation in a cell culture model of Huntington's disease. Hum Mol Genet. 2001;10:1307-15.

170. Cha JRC, St., KJH L, Tradewell ML, Gentil BJ, Minotti S, Jaffer ZM, Chen R, Rubenstein AE, Durham HD. A novel small molecule HSP90 inhibitor, NXD30001, differentially induces heat shock proteins in nervous tissue in culture and in vivo. Cell Stress Chaperon. 2014;19:421-35.

171. Neef DW, Turski ML, Thiele DJ. Modulation of heat shock transcription factor 1 as a therapeutic target for small molecule intervention in neurodegenerative disease. PLoS Biol. 2010;8:e1000291.

172. Wang P, Wander CM, Yuan CX, Bereman MS, Cohen TJ. Acetylation-induced TDP-43 pathology is suppressed by an HSF1-dependent chaperone program. Nat Commun. 2017:8:82.

173. Jiang YQ, Wang XL, Cao XH, Ye ZY, Li L, Cai WQ. Increased heat shock transcription factor 1 in the cerebellum reverses the deficiency of Purkinje cells in Alzheimer's disease. Brain Res. 2013;1519:105-11.

174. Mimoto T, Morimoto N, Miyazaki K, Kurata T, Sato K, Ikeda Y, Abe K. Expression of heat shock transcription factor 1 and its downstream target protein T-cell death associated gene 51 in the spinal cord of a mouse model of amyotrophic lateral sclerosis. Brain Res. 2012;1488:123-31.

175. Zinkie S, Gentil BJ, Minotti S, Durham HD. Expression of the protein chaperone, clusterin, in spinal cord cells constitutively and following cellular stress, and upregulation by treatment with Hsp90 inhibitor. Cell Stress Chaperon. 2013;18:745-58

176. Crippa V, Sau D, Rusmini P, Boncoraglio A, Onesto E, Bolzoni E, Galbiati M, Fontana E, Marino M, Carra S, et al. The small heat shock protein B8 (HspB8) promotes autophagic removal of misfolded proteins involved in amyotrophic lateral sclerosis (ALS). Hum Mol Genet. 2010;19:3440-56.

177. Marino M, Papa S, Crippa V, Nardo G, Peviani M, Cheroni C, Trolese MC, Lauranzano $\mathrm{E}$, Bonetto $\mathrm{V}$, Poletti $\mathrm{A}$, et al. Differences in protein quality control correlate with phenotype variability in 2 mouse models of familial amyotrophic lateral sclerosis. Neurobiol Aging. 2015;36:492-504.

178. Wang J, Slunt H, Gonzales V, Fromholt D, Coonfield M, Copeland NG, Jenkins NA, Borchelt DR. Copper-binding-site-null SOD1 causes ALS in transgenic mice: aggregates of non-native SOD1 delineate a common feature. Hum Mol Gen. 2003;12:2753-64.

179. Vlug AS, Teuling E, Haasdijk ED, French P, Hoogenraad CC, Jaarsma D. ATF3 expression precedes death of spinal motoneurons in amyotrophic lateral sclerosis-SOD1 transgenic mice and correlates with c-Jun phosphorylation, CHOP expression, somato-dendritic ubiquitination and Golgi fragmentation. Eur J Neurosci. 2005;22:1881-94.

180. Zourlidou A, Gidalevitz T, Kristiansen M, Landles C, Woodman B, Wells DJ, Latchman DS, de Belleroche J, Tabrizi SJ, Morimoto RI, Bates GP. Hsp27 Overexpression in the R6/2 mouse model of Huntington's disease: chronic neurodegeneration does not induce Hsp27 activation. Hum Mol Genet. 2007;16:1078-90.

181. Hansson O, Nylandsted J, Castilho RF, Leist $M$, Jäättelä M, Brundin P. Overexpression of heat shock protein 70 in R6/2 Huntington's disease mice has only modest effects on disease progression. Brain Res. 2003;970:47-57.

182. Labbadia J, Novoselov SS, Bett JS, Weiss A, Paganetti P, Bates GP, Cheetham ME. Suppression of protein aggregation by chaperone modification of high molecular weight complexes. Brain. 2012;135:1180-96.

183. Vacher C, Garcia-Oroz L, Rubinsztein DC. Overexpression of yeast hsp104 reduces polyglutamine aggregation and prolongs survival of a transgenic mouse model of Huntington's disease. Hum Mol Genet. 2005;14:3425-33.

184. Hayashida N, Fujimoto M, Tan K, Prakasam R, Shinkawa T, Li L, Ichikawa H, Takii R, Nakai A. Heat shock factor 1 ameliorates proteotoxicity in cooperation with the transcription factor NFAT. EMBO J. 2010;29:3459-69.

185. Shinkawa T, Tan K, Fujimoto M, Hayashida N, Yamamoto K, Takaki E, Takii R, Prakasam R, Inouye S, Mezger $V$, Nakai A. Heat shock factor 2 is required for maintaining proteostasis against febrile-range thermal stress and polyglutamine aggregation. Mol Biol Cell. 2011;22:3571-83. 